\title{
USO DE HABITAT POR Caiman crocodilus E Paleosuchus palpebrosus NO RESERVATÓRIO DA UHE DE LAJEADO, TOCANTINS
}

\author{
ANDRÉ Martins VillaÇa
}

Dissertação apresentada à Escola Superior de Agricultura "Luiz de Queiroz", Universidade de São Paulo, para obtenção do título de Mestre em Ecologia de Agroecossistemas.

P I R A C I C A B A

Estado de São Paulo - Brasil

Novembro - 2004 


\title{
USO DE HABITAT POR Caiman crocodilus E Paleosuchus palpebrosus NO RESERVATÓRIO DA UHE DE LAJEADO, TOCANTINS
}

\author{
André Martins Villaça \\ Biólogo
}

Orientador: Prof. Dr. LUCIANO MARTINS VERDADE

\begin{abstract}
Dissertação apresentada à Escola Superior de Agricultura "Luiz de Queiroz", Universidade de São Paulo, para obtenção do título de Mestre em Ecologia de Agroecossistemas.
\end{abstract}

P I R A C I C A B A

Estado de São Paulo - Brasil

Novembro - 2004 


\section{Dados Internacionais de Catalogação na Publicação (CIP) DIVISÃO DE BIBLIOTECA E DOCUMENTAÇÃO - ESALQ/USP}

Villaça, André Martins

Uso de habitat por Caiman crocodilus e Paleosuchus palpebrosus no reservatório da UHE de Lajedo, Tocantins / André Martins Villaça. - - Piracicaba, 2004.

59 p. : il.

Dissertação (Mestrado) - - Escola Superior de Agricultura Luiz de Queiroz, 2004.

Bibliografia.

1. Bacia hidrográfica 2. Habitat - Uso 3. Jacaré 4. Reservatório 5. Tocantins, Rio 6. Usinas hidrelétricas I. Título

CDD 639.394

"Permitida a cópia total ou parcial deste documento, desde que citada a fonte - O autor" 
Salve o Corinthians, O campeão dos campeões, Eternamente Dentro dos nossos corações

Salve o Corinthians De tradições e glórias mil Tu és o orgulho Dos esportistas do Brasil

Teu passado é uma bandeira, Teu presente, uma lição Figuras entre os primeiros Do nosso esporte bretão

Corinthians grande, Sempre altaneiro És do Brasil O clube mais brasileiro (Lauro d'Ávila) 
À Carla, pelo amor e cumplicidade, à Marília, pelo sentimento indescritível que me trouxe e aos meus pais e irmãos, pelo amor e total apoio nas minhas escolhas

Dedico 


\section{AGRADECIMENTOS}

Ao Professor Dr. Luciano Martins Verdade, pela orientação.

Ao Professor Dr. Carlos Alberto Vettorazzi, pelas valiosas sugestões de análise na parte do sensoriamento remoto.

Ao pesquisador Dr. Flavio de Barros Molina (Zôo - SP) pelo incentivo à pós-graduação e participação em meu comitê de orientação.

Ao Pesquisador Dr. Carlos Afonso Nobre (INPE), pelas imagens gentilmente cedidas da área estudada.

Ao amigo herpetólogo Daniel Fernandes da Silva (MN/UFRJ), o "Bauru" ou "Pedra Noventa", pelo companheirismo durante as campanhas no Tocantins e pelo resumo em inglês.

À ecóloga Kátia Ferraz, ao engenheiro florestal Sílvio Ferraz e ao ictiólogo Pedro Gerhard, pela amizade e fundamentais contribuições neste estudo.

Ao povo do LEA (Laboratório de Ecologia Animal) e colegas de profissão: Adenilson Cavalcanti, Alexander Christianini, Alexandre Vogliotti, Anderson Ferreira, Carla Gheler, Cláudia Campos, Diego Queirolo, Érica Haller, Fábio Comin, Graziela Dotta, Marli Penteado, Rafael Barbieri, Vitor Cantarelli, pela amizade e colaboração no trabalho.

Ao Dr. Carlos Ignácio Pina e à Profa. Dra. Eliana Matushima, pelas importantes sugestões, análises e correções.

À bióloga Maria Amélia Maciel (Projeto Fauna ULBRA / INVESTCO) pela oportunidade de trabalho, acolhimento em Palmas e competência quanto ao ótimo apoio logístico. 
À veterinária Geisa Leite Goulart, pelo auxílio e coleguismo durante as campanhas e aos auxiliares de campo Aldo Franck, Divino Lopes, Fernando Oliveira, Jaime dos Santos, José Trindade, Josué da Silva e Seminho Borges (Projeto Fauna ULBRA / INVESTCO), pelos inesquecíveis episódios vividos e extrema competência durante as focagens noturnas de jacarés.

Aos amigos: Beto, Carlos, Fabíola, Marô, Paula, Tatiana e aos familiares César, Danilo, Fernanda, Nivaldo e Norma pela carinhosa companhia à Carla durante minhas viagens. À moçada da biologia e da Biosfera: Benedito, Hadija, Ixalá, Menos um, Neto, Pastor, Prisioneiro, Sapão, Tamaguxi e Xuleta pelas risadas fáceis desta fase da vida. E a todos que de forma ou outra contribuíram para a realização desta pesquisa. 


\section{SUMÁRIO}

\begin{tabular}{|c|c|}
\hline & Página \\
\hline LISTA DE FIGURAS............ & vix \\
\hline 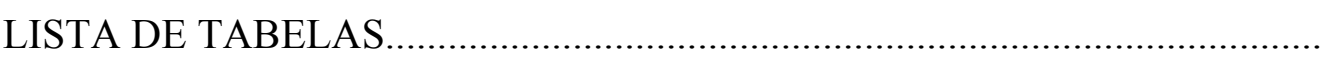 & $\mathrm{xi}$ \\
\hline RESUMO... & xii \\
\hline SUMMARY .......................... & xiv \\
\hline 1 INTRODUÇÃO............................. & 1 \\
\hline 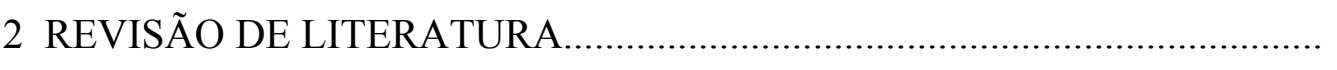 & 3 \\
\hline 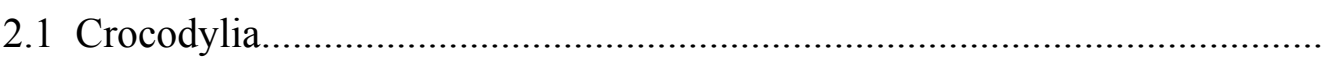 & 3 \\
\hline 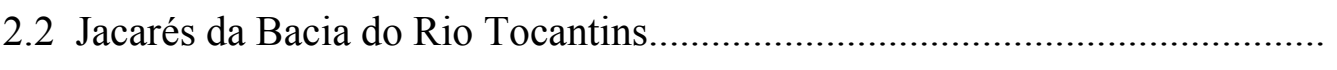 & 4 \\
\hline 2.2.1 Melanosuchus niger.......................................... & 5 \\
\hline 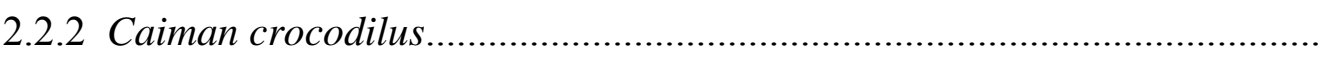 & 6 \\
\hline 2.2.3 Paleosuchus palpebrosus......... & 7 \\
\hline 2.2.4 Simpatria das espécies............... & 8 \\
\hline 2.3 Usinas Hidrelétricas no Brasil..... & 8 \\
\hline 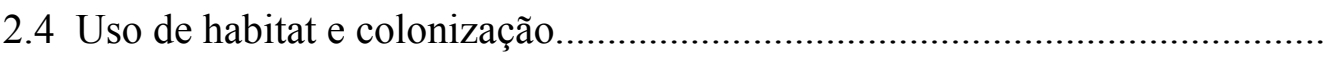 & 10 \\
\hline 3 MATERIAL E MÉTODOS................ & 13 \\
\hline 3.1 Área de estudo. & 13 \\
\hline
\end{tabular}




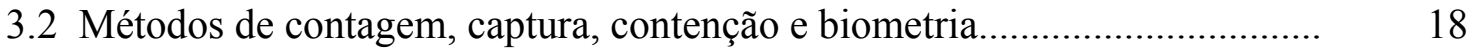

3.3 Classificação da imagem por meio do sensoriamento remoto....................... 20

3.3.1 Distribuição espacial de jacarés em relação às classes identificadas pela classificação da imagem............................................................................. 20

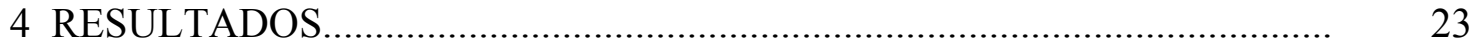

4.1 Abundância, taxa entre os sexos e distribuição pseudo-etária........................ 23

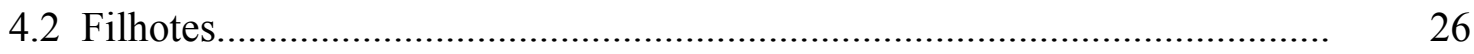

4.3 Descrição dos habitats ocupados pelos jacarés.............................................. 27

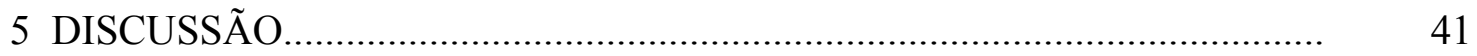

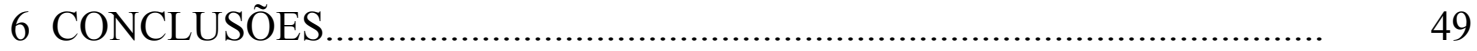

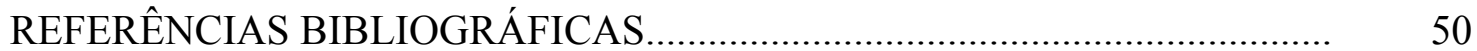




\section{LISTA DE FIGURAS}

Página

1 Mapa do Brasil realçando a distribuição do Domínio do Cerrado e Pantanal. notar região do Estado do Tocantins......................................

2 Localização do reservatório da Usina Hidrelétrica de Lajeado, Estado de Tocantins.

3 Composição colorida (LANDSAT TM) das bandas 2, 3 e 4 para a área do reservatório da UHE Lajeado, TO, data de 09 de julho de 2003, indicando as cinco regiões monitoradas......

4 Rio Tocantins na área de estudo pré-enchimento (25/06/2001) (Fonte:

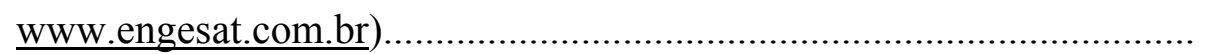

5 Rio Tocantins na área de estudo pós-enchimento (27/05/2002) (Fonte: www.engesat.com.br).

6 Exemplo da faixa amostral considerada para o cálculo da área de cada mancha de habitat.

7 Freqüência absoluta e freqüência relativa (\%) para cada espécie e indeterminados, somadas as cinco campanhas....................................

8 Número de animais observados (excluindo os filhotes), para as espécies C. crocodilus, $P$. palpebrosus e indeterminados no reservatório da UHE de Lajeado, TO, em cada campanha.

9 Distribuição das espécies de Crocodilianos nas diferentes manchas de habitat do Reservatório de Lajeado, TO 
10 Distribuição das espécies de Crocodilianos nas manchas de habitat da Região do Lajeado, no Reservatório de Lajeado, TO.......................... $\quad 30$

11 Distribuição das espécies de Crocodilianos nas manchas de habitat da Região do Palmas, no Reservatório de Lajeado, TO............................. $\quad 30$

12 Distribuição das espécies de Crocodilianos nas manchas de habitat da Região do Aeroporto, no Reservatório de Lajeado, TO........................ 31

13 Distribuição das espécies de Crocodilianos nas manchas de habitat da Região de Porto Nacional, no Reservatório de Lajeado, TO

14 Distribuição das espécies de Crocodilianos nas manchas de habitat da Região de Brejinho de Nazaré, no Reservatório de Lajeado, TO.......... 32

15 Distribuição das espécies de Crocodilianos nas manchas de habitat da Região do Aeroporto, margem direita. Verificar ocorrências na mancha 1 correspondente ao buritizal..................................................

16 Densidade para C. crocodilus, P. palpebrosus e indeterminados nas manchas classificadas

17 Número de visualizações de crocodilianos, por campanha, em cada mancha de habitat definida.

18 Freqüência relativa de visualizações de crocodilianos, por campanha, em cada mancha de habitat definida.

19 Número de visualizações de C. crocodilus por campanha e por mancha de habitat.

20 Número de visualizações de $P$. palpebrosus por campanha e por mancha de habitat.

21 Número de visualizações de indeterminados por campanha e por mancha de habitat

22 Freqüência absoluta das espécies, C. crocodilus e $P$. palpebrosus, nas manchas de habitat determinadas somadas todas as campanhas.............

23 Freqüência relativa das espécies, C. crocodilus e $P$. palpebrosus, nas manchas de habitat determinadas somadas todas as campanhas 


\section{LISTA DE TABELAS}

Página

1 Número de indivíduos identificados e indeterminados quanto à espécie, em cada campanha realizada (valores gerais por espécie e sem os filhotes).

2 Distribuição entre os sexos de C. crocodilus e P. palpebrosus capturados

3 Distribuição das espécies em classes de tamanho conforme proposto por Ayarzagüena (1983) para C. crocodilus: Classe I - $\mathbf{x}<200$; Classe II $-200<\mathrm{x}<599$; Classe III $-600<\mathrm{x}<899$ e Classe IV $-900<\mathrm{x}$ (valores em $\mathrm{mm})$.

4 Relação das classes identificadas e o número de animais observados (excluindo os filhotes)

5 Tabela 5. Área total e amostrada $\left(\mathrm{km}^{2}\right)$ das manchas de habitat aquático classificadas, abundância ( $\mathrm{n}^{\mathrm{o}}$. de ind.) e densidade (ind. $/ \mathrm{km}^{2}$ ) de cada espécie e total de crocodilianos (somados os indeterminados) por mancha de habitat amostrado. Manchas: 1) Buritizal; 2) água com sedimento; 3) margem rasa; 5) solo arenoso; 6) vegetação seca 1; 7) vegetação seca 2 ; 8) vegetação seca 3; e 9) gramíneas 


\title{
USO DE HABITAT POR Caiman crocodilus E Paleosuchus palpebrosus NO RESERVATÓRIO DA UHE DE LAJEADO, TOCANTINS
}

\author{
Autor: ANDRÉ MARTINS VILLAÇA \\ Orientador: Prof. Dr. LUCIANO MARTINS VERDADE
}

\section{RESUMO}

A construção de reservatórios modifica drasticamente a paisagem transformando um ambiente lótico em lêntico e criando uma nova linha de margem com características muitas vezes diferentes. Estes novos habitats são passíveis a utilização e colonização por diversas espécies. Com relação aos crocodilianos existem registros de ocorrência para três espécies nesta região Caiman crocodilus, Paleosuchus palpebrosus e Melanosuchus niger. O presente estudo verificou abundância, densidade, taxa entre os sexos e o uso de habitat para as espécies C. crocodilus e P. palpebrosus, encontradas no reservatório em um período de dez meses de monitoramento pós-represamento. Para efetuar as observações e capturas de indivíduos, focagens noturnas em barco a motor foram realizadas ao longo de cinco campanhas bimestrais. Foram visualizados 659 jacarés sendo 259 C. crocodilus, 102 P. palpebrosus e 298 indeterminados. Nenhum exemplar da espécie M. niger foi observado. O número de crocodilianos por campanha não variou de forma significativa, sendo C. crocodilus mais freqüente. Foram efetuadas 75 capturas,

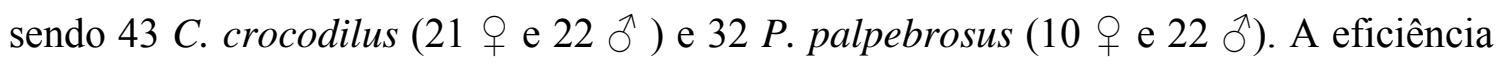


de captura foi de $16,60 \%$ para $C$. crocodilus, $31,37 \%$ para $P$. palpebrosus e $11,38 \%$ para ambas as espécies considerando também os indeterminados. A captura de exemplares de P. palpebrosus foi mais eficiente se comparada a de C. crocodilus. Foram capturados 29 filhotes entre o final da estação chuvosa e o pico da estação seca, nas três últimas campanhas, evidenciando reprodução pós-represamento, sendo 26 C. crocodilus e $3 P$. palpebrosus. Os filhotes de C. crocodilus foram observados agrupados em três regiões diferentes sendo que um destes agrupamentos se manteve no mesmo local pelas três últimas campanhas apresentando redução paulatina do número de filhotes. Os três filhotes agrupados de $P$. palpebrosus só foram observados na quinta campanha. A classificação não-supervisionada de imagens LANDSAT - TM, resultou em oito classes (manchas de habitats) representando $93 \%$ da área. Tais manchas foram caracterizadas a partir de anotações de campo e interpretação da imagem. A macha 1, caracterizada como um buritizal alagado próximo ao aeroporto, foi a que apresentou as maiores densidades 60 e $110 \mathrm{ind} / \mathrm{km}^{2}$ para C. crocodilus e P. palpebrosus respectivamente, explicada pela reduzida área ocupada por este habitat. A mancha 2 foi caracterizada como água com sedimento apresentando os maiores valores para área total e amostrada e conseqüentemente baixas densidades. A mancha 3 caracterizada como margem rasa apresentou a maior abundância para C. crocodilus. A mancha 5 caracterizada como solo arenoso não se destacou por elevadas densidades sendo porém a mais abundante para $P$. palpebrosus. As manchas 6,7 e 8 se agrupadas mediante a caracterização como habitats de vegetação seca apresentam a segunda maior densidade com $27,55 \mathrm{ind} / \mathrm{km}^{2}$. A mancha 9 foi caracterizada como um habitat onde ocorria a presença de gramíneas (pasto e cerrado campo limpo) sendo C. crocodilus a espécie predominante neste habitat. Conclui-se com este trabalho que C. crocodilus e P. palpebrosus são as espécies de crocodilianos encontradas na região do reservatório e não se mostram relativamente vulneráveis, em um primeiro momento, devido ao represamento do rio. C. crocodilus é mais abundante do que $P$. palpebrosus no reservatório. C. crocodilus é mais seletivo quanto ao uso das manchas de habitats definidos A observação de grupos de filhotes corrobora para o fato destas espécies se adequarem ao novo ambiente. 


\title{
Caiman crocodilus AND Paleosuchus palpebrosus HABITAT USE IN LAJEADO DAM, TOCANTINS, BRAZIL
}

\author{
Author: ANDRÉ MARTINS VILLAÇA \\ Adviser: Prof. Dr. LUCIANO MARTINS VERDADE
}

\section{SUMMARY}

The construction of river dams modifies drastically the local landscape, changing a lotic environment into a lentic one and, therefore, originating a new river edge, generally with quite different features. These new habitats could be used and occupied by a plenty of species. There are many projects, constructions and dams in most of its main rivers. Regarding the crocodilians, there are three species recorded in this region: Caiman crocodilus, Paleosuchus palpebrosus, and Melanosuchus niger. The present study verified the abundance, density, sex ratio, and habitat use of Caiman crocodilus and Paleosuchus palpebrosus. These species were found in the dam during a monitoring period of ten months carried out after flooding. Observations and captures were performed during nocturnal surveys using a motorboat. The surveys occurred in five campaigns with intervals of two months. 659 crocodilians, 259 C. crocodilus, $102 P$. palpebrosus and 298 undetermined were visualized considering all campaigns. None specimens of $M$. niger were observed. The number of crocodilians by campaign did not show significant variation and C. crocodilus was the most frequent species. We captured

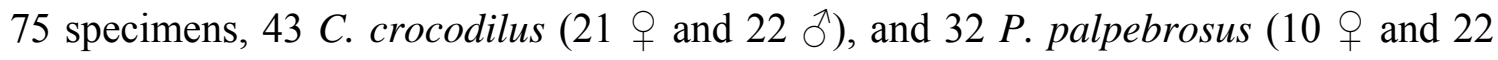


đ). Capture effectiveness was $16.60 \%$ for C. crocodilus, $31.37 \%$ for $P$. palpebrosus, and $11.38 \%$ for both species considering the undetermined specimens. Capture of specimens of $P$. palpebrosus was more effective compared to C. crocodilus. Twenty nine hatchlings (26 C. crocodilus and $3 P$. palpebrosus) were captured between the end of rainy season and the peak of dry season (during the last three campaigns), suggesting reproductive activity after flooding. Hatchlings of $C$. crocodilus were observed in groups in three different areas. One of these groupings was in the same place during the last three campaigns, showing a slight decrease in number of hatchlings. The three hatchlings of $P$. palpebrosus were observed only in the last campaign. The unsupervised classification of the LANDSAT - TM images, resulted in eight classes (habitat patches) which represented $93 \%$ of the dam. The patches were characterized based on field notes and image interpretation. Patch 1, characterized as a flooded "buritizal" near the airport, showed the highest density (60 and 110 individuals $/ \mathrm{km}^{2}$ of the C. crocodilus and $P$. palpebrosus, respectively). Patch 2 was characterized by water with sediments, representing a great percentage of the sampled and total area and, consequently, showed the lowest density of crocodiles. Patch 3 represents shallow edges and showed the largest abundance of C. crocodilus. Patch 5 represents sandy grounds and, even though this habitat showed no high densities, $P$. palpebrosus was more abundant in this habitat. Patches 6, 7 and 8 were considered as dry vegetation, showing the second major density (27.55 individuals $/ \mathrm{km}^{2}$ ). Patch 9 was characterized by the presence of grass (pasture and "cerrado campo limpo") and C. crocodilus was the predominant species in this habitat. It can be concluded that $C$. crocodilus e $P$. palpebrosus are the species that occur in the dam and, apparently, they are not vulnerable due to the river modifications. $C$. crocodilus is more abundant than P. palpebrosus in the study area. C. crocodilus is more selective than $P$. palpebrosus in function of habitat patches. The presence of hatchlings corroborate to the species adaptation to the new habitats. 


\section{INTRODUÇÃO}

A geração de energia elétrica é fundamental para o desenvolvimento de uma região. No Brasil, devido às condições geográficas, tal geração se realiza preponderantemente através de Usinas Hidrelétricas (UHEs), que geralmente trazem consigo enormes reservatórios formados devido ao represamento de rios. $\mathrm{O}$ impacto ambiental causado por tal modificação é ainda pouco estudado.

A conservação das bacias hidrográficas é fundamental para a conservação das espécies de crocodilianos, desta forma a rápida transformação de um ambiente lótico em lêntico, que ocorre durante a instalação de UHEs, deve ser compreendida como uma provável responsável por modificações na dinâmica populacional de seus integrantes, entre eles os jacarés. Isto posto, torna-se claro que estudos referentes à ecologia das espécies em períodos pré, durante e pós-enchimento de reservatórios pertencentes à UHEs, são fundamentais para a correta diagnose de eventual declínio, crescimento ou mesmo equilíbrio populacional.

O Rio Tocantins atualmente é um dos principais rios do Cerrado brasileiro, sendo o principal rio de uma bacia hidrográfica caracterizada entre outros aspectos, pela transição Cerrado e Floresta Amazônica. Algumas descrições de espécies e escassos estudos têm ocorrido para esta área, necessitando ainda de mais pesquisas para obtenção de informações que subsidiem a conservação desta bacia.

A existência de projetos de construção de UHEs (sendo alguns já em andamento) devido ao alto potencial hidrelétrico da Bacia do Tocantins, faz com que o mesmo processo ocorrido no Rio Tietê durante a instalação de suas usinas, ocorra agora no Rio Tocantins. Tal processo é responsável pela alteração da dinâmica fluvial mediante o 
represamento do rio em diversos pontos (UHEs) e provavelmente também altera a dinâmica das populações integrantes deste habitat.

O presente estudo teve como objetivo geral comparar o processo de uso de habitat de ambientes antropizados, através do sensoriamento remoto, criados a partir da construção do reservatório da UHE de Lajeado, em um curto período (10 meses) pósrepresamento pelas espécies nativas de jacarés. A abundância e densidade (em função da caracterização das manchas de habitat aquáticos definidas por sensoriamento remoto), eficiência de captura, razão sexual e a verificação de ocorrência de reprodução pósrepresamento das espécies também foram analisadas. 


\section{REVISÃO DE LITERATURA}

\subsection{Crocodylia}

A ordem Crocodylia compreende os atuais jacarés, caimans e aligatores (família Alligatoridae - regiões Holártica e Neotropical); crocodilos (família Crocodylidae regiões Neotropical, Etiópica, Oriental e Australiana) e gaviais (família Gavialidae região Oriental) (Höfling et al., 1995; Pough et al., 1998; Zug et al., 2001). Possui atualmente 23 espécies distribuídas em 8 gêneros, e os indícios mais antigos deste grupo datam do período Triássico superior, há cerca de 205 milhões de anos (Pough et al., 1993).

No Brasil ocorrem seis espécies, sendo todas da família Alligatoridae: Jacaré do papo amarelo (Caiman latirostris), Jacaretinga (Caiman crocodilus), Jacaré do Pantanal (Caiman yacare), Jacaré-coroa ou Jacaré-pagua (Paleosuchus palpebrosus), Jacarécoroa (Paleosuchus trigonatus) e Jacaré-açu (Melanosuchus niger) (Yamashita et al., 1993). Estes animais estão sempre associados aos corpos d'água, bem como à vegetação que ocupa as margens de rios, riachos, lagos e lagoas (Medem, 1983; Herron, 1994; Magnusson, 1995).

Estudos demonstram que existe uma relação entre os tipos de habitat utilizados pelas diferentes espécies de crocodilianos e sua susceptibilidade à extinção, sendo que para algumas delas a conservação dos ambientes aquáticos parece ser relativamente suficiente para a manutenção das espécies (Magnusson, 1986; 1995). No entanto, os impactos causados pela alteração das condições naturais de bacias hidrográficas (e.g. represamento de cursos de água, agricultura, atividades de mineração) em áreas com populações de crocodilianos ainda é desconhecido (Magnusson, 1995). 
Outros estudos apontam também uma ligação entre habitat e comunicação sonora, sugerindo que animais de ambientes mais fechados (e.g. floresta tropical) possam apresentar vocalizações mais intensas (Lang, 1987; Piffer \& Verdade 2002).

A conservação das espécies nativas de crocodilianos através do incentivo à implantação de criatórios já vem ocorrendo em alguns países (Verdade, 1997) e propicia a produção de itens, tais como o couro e a carne. Estes produtos apresentam boa aceitação no mercado, que ainda conta com uma considerável parcela abastecida pelo comércio e caça ilegais de diversos países (Brazaitis, 1989; Thorbjarnarson, 1992; Ross, 1998). Desta forma, para a manutenção do equilíbrio das espécies de crocodilianos é necessário que ocorra: 1) controle eficaz sobre a caça indiscriminada, capaz de promover alterações significativas na dinâmica populacional destes animais (Mourão \& Magnusson, 1997); 2) estudos relacionados à ecologia de populações em paisagens antropizadas (Piña et al., 2004); 3) manejo ambiental em áreas rigorosamente determinadas que visem o aproveitamento sustentável de recursos (Ross, 1998).

\subsection{Jacarés da Bacia do Rio Tocantins}

O Rio Tocantins é um típico rio do Cerrado brasileiro e tal qual o bioma a que pertence, ainda são muitas as espécies animais a serem descritas nesta importante bacia hidrográfica do país. No caso da herpetofauna o Estado do Tocantins é considerado como uma região prioritária para realizações de inventários (Brasil, 2002), mesmo as espécies comuns e com ampla distribuição geográfica são pobremente representadas em coleções científicas e muitas regiões permanecem ainda completamente inexploradas (Heyer, 1988). Um grande número de espécies novas tem sido descrito recentemente (e.g. Vanzolini, 1994; 1995; 1997; Caramaschi, 1996; Pombal \& Bastos, 1996; Rodrigues, 1996; Colli et al., 1998). Estudos sobre diferentes grupos faunísticos no Domínio do Cerrado ainda são raros (e.g. Vanzolini \& Heyer, 1988; Strüssmann, 2000) e um considerável esforço de amostragem é ainda necessário para identificar os padrões de distribuição da fauna (Coutinho et al., 2002).

Nas bacias hidrográficas situadas no Domínio do Cerrado brasileiro (Figura 1) existem quatro espécies de crocodilianos: $M$. niger, C. crocodilus, C. yacare e $P$. 
palpebrosus. Todas estas espécies também apresentam suas respectivas distribuições geográficas associadas à Bacia Amazônica (Medem, 1983; Thorbjarnarson, 1992; Yamashita et al., 1993; Ross, 1998). Para o Rio Tocantins existem registros de três destas espécies: M. niger, C. crocodilus e P. palpebrosus.

\subsubsection{Melanosuchus niger}

Melanosuchus niger Distribui-se preponderantemente na Bacia Amazônica (Medem, 1983; Plotkin et al., 1983; Peres \& Carkeek, 1993; Brazaitis et al., 1996), porém Da Silveira (2002) alerta para o fato da espécie estar associada a florestas inundáveis. Existem registros e relatos de indivíduos em alguns rios característicos de cerrado como o Araguaia, Tocantins e seus tributários (Medem, 1983). Tais populações, no entanto, encontram-se bastante fragmentadas (Brazaitis et al., 1996), fato que pode estar associado à constante perda de habitat devido aos intensos processos de antropização e/ou a uma possível exploração excessiva desta espécie, que conhecidamente sofre forte pressão de caça (Ross, 1998).

A maioria dos autores em suas publicações considera $M$. niger como uma espécie ameaçada de extinção (Plotkin et al., 1983; Hall, 1991; Thorbjarnarson, 1992; Herron, 1994; Da Silveira et al, 1997, entre outros), esta espécie está avaliada atualmente pela União Mundial para a Natureza (IUCN - Categoria EN - 'Endangered') e Convenção sobre o Comércio Internacional das Espécies da Flora e Fauna Selvagem em Perigo de Extinção (CITES - Apêndice I) como uma espécie em risco de extinção (Ross, 1998). Entretanto, em algumas regiões da Amazônia (e.g. Bacia dos rios Negro e Solimões), existem populações extremamente numerosas que poderiam ser manejadas de maneira legal (Da Silveira, 2002). Esta espécie foi recentemente retirada da lista nacional das espécies da fauna brasileira ameaçadas de extinção (Brasil, 2003). 


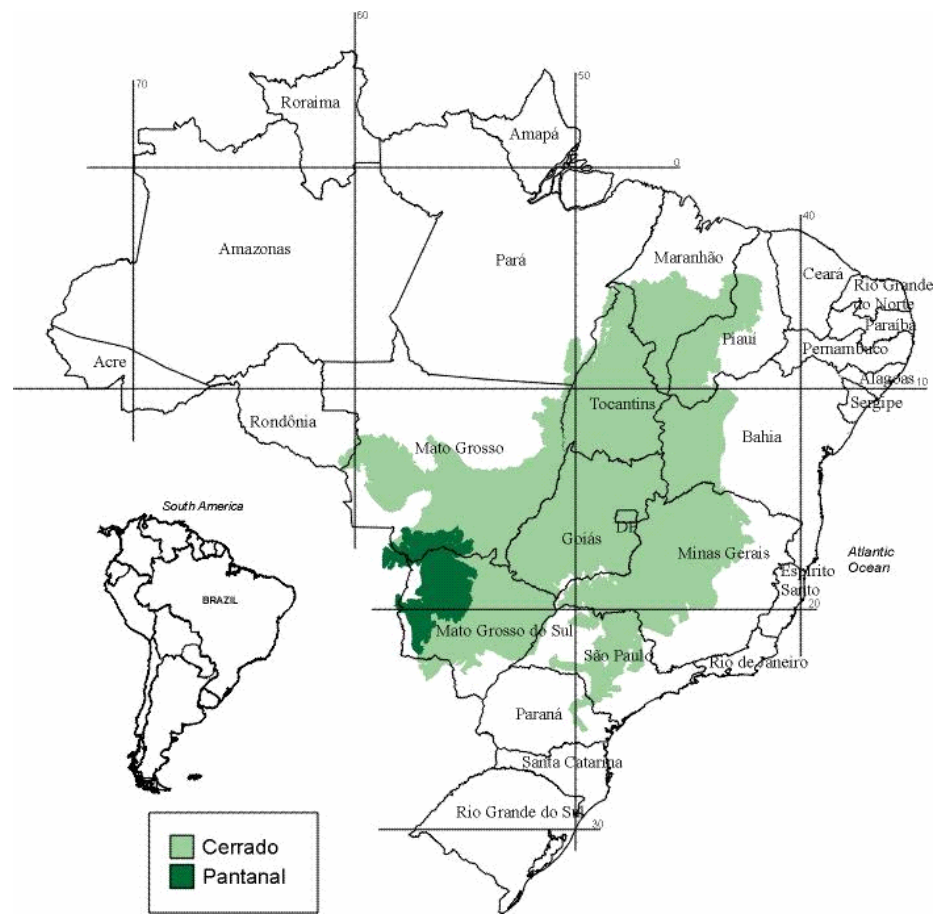

Figura 1 - Mapa do Brasil realçando a distribuição do Domínio do Cerrado e Pantanal. notar região do Estado do Tocantins

A IUCN avalia que a realização de estudos de ecologia básica nas áreas de ocorrência, o desenvolvimento de programas de manejo ambiental visando sua conservação e a fiscalização eficiente sobre o comércio ilegal de carne e pele são projetos de alta prioridade para esta espécie (Ross, 1998).

\subsubsection{Caiman crocodilus}

Caiman crocodilus (Caiman sclerops aparece em algumas publicações como um importante sinônimo para esta espécie) está avaliado pela IUCN (categoria LR - 'Lower Risk') e CITES (Apêndice II) como uma espécie em baixo risco de extinção (Ross, 1988). 
Este grupo forma um táxon bastante complexo que inclui atualmente quatro subespécies: C. crocodilus fuscus, C. crocodilus apaporiensis, C. crocodilus chiapasius e C. crocodilus crocodilus (Thorbjarnarson, 1992; Brazaitis et al., 1996; Ross, 1998). Se associarmos a esse complexo C. yacare, considerando-o uma quinta subespécie $C$. crocodilus yacare como fazem alguns autores (Yamashita, 1993; Campos et al., 2003) teremos um grupo com enorme distribuição no continente americano, habitando desde o sudeste do México, na América do Norte, até o norte da Argentina, na América do Sul, (Ayarzagüena, 1983; Medem, 1983; Webb et al., 1987; Gorzula \& Seijas, 1989; Thorbjarnarson, 1992; Brazaitis et al., 1996; Ross, 1998).

King \& Burke (1989) sugeriram a elevação da antiga categoria referente à subespécie C. crocodilus yacare para o nível específico C. yacare. Como existem áreas, especialmente no domínio do Cerrado, onde estão registradas ocorrências tanto de $C$. crocodilus como C. yacare, alguns autores apontam para a possibilidade de hibridização entre as espécies o que dificultaria ainda mais a resolução dos problemas referentes à taxonomia e distribuição geográfica do grupo (Busack \& Pandya, 2001).

$\mathrm{Na}$ região onde foi realizado o presente estudo os indivíduos amostrados são classificados como pertencentes à subespécie C. crocodilus crocodilus. Neste trabalho, os animais serão denominados como C. crocodilus, ou Jacaretinga (IUCN, 1982).

A IUCN indica para esta espécie no Brasil projetos com moderada prioridade entre eles a implementação de programas de manejo sustentável, a diminuição do comércio ilegal de peles e estudos taxonômicos aprofundados que definam mais precisamente as espécies e/ou subespécies e suas respectivas distribuições geográficas.

\subsubsection{Paleosuchus palpebrosus}

Paleosuchus palpebrosus foi avaliado pela IUCN (categoria LR - 'Lower risk') e CITES (Apêndice II) como uma espécie em baixo risco de extinção (Ross, 1998). Sua distribuição geográfica compreende as bacias dos rios Orinoco, Amazonas, Tocantins e São Francisco, além de populações limitadas aos rios Paraná e Paraguai (Medem, 1983; Scott et al., 1990; Thorbjarnarson, 1992; Ross, 1998). 
Assim como M. niger e C. crocodilus, P. palpebrosus também se distribui em rios típicos de Cerrado não sendo, portanto exclusivamente amazônicos. Trata-se provavelmente da menor espécie de crocodiliano conhecido e por seu couro apresentar formações ósseas internamente às escamas, pode-se supor que a pressão de caça humana para esta espécie seja menos intensa se compararmos com M. niger e C. crocodilus. Devido à escassez de dados para esta espécie a IUCN classifica como projeto de prioridade moderada, investigações sobre a biologia e ecologia de populações a serem realizadas principalmente na Bacia Amazônica (Ross, 1998).

\subsubsection{Simpatria das espécies}

Para as três espécies acima citadas existem relatos de ocorrência na Bacia do Rio Tocantins, caracterizando simpatria nesta região localizada em uma zona de transição de Floresta Amazônica para o Cerrado (Lacher \& Alho, 2001). Os rios e matas de galeria presentes no cerrado brasileiro confluem na maioria dos casos em direção à Bacia Amazônica, servindo de verdadeiros corredores úmidos para diversas espécies da fauna associada a estes biomas (Redford \& da Fonseca, 1986).

A distribuição geográfica de C. crocodilus é altamente relacionada à de $M$. niger (Ayarzagüena, 1983; Medem, 1983; Webb et al., 1987; Gorzula \& Seijas, 1989; Thorbjarnarson, 1992; Brazaitis et al., 1996; Da Silveira et al, 1997; Ross, 1998). Estudos relacionados à interação destas espécies ainda são escassos. Se acrescentarmos ainda a ocorrência da espécie $P$. palpebrosus nestes mesmos habitats, verificaremos que em algumas bacias hidrográficas temos a ocorrência simpátrica destas três espécies de crocodilianos.

\subsection{Usinas Hidrelétricas no Brasil}

Mais de $95 \%$ da energia elétrica consumida no país é proveniente de usinas hidrelétricas (UHEs), cujo local de instalação depende basicamente da existência de um desnível relativamente acentuado e/ou grande volume d'água. No caso do Brasil, devido 
à sua geografia, rios que apresentam grande vazão (Paraná, Tietê, Tocantins, São Francisco) não oferecem grandes desníveis ao longo de suas extensões. Desta forma a construção de barragens formando grandes reservatórios de água é a prática mais comum para a geração de energia elétrica ${ }^{1}$ (Müller, 1995).

A construção de tais reservatórios promove a transformação de um ambiente lótico em lêntico, modificando drasticamente a dinâmica fluvial e conseqüentemente seus componentes bióticos e abióticos. A formação de um reservatório implica na destruição total do habitat (Müller, 1995). A realização de estudos ecológicos que visem o monitoramento da biota afetada em períodos pré, durante e pós-enchimento, não só é obrigatória (Resolução CONAMA n001/86), mas aparece também como uma ótima oportunidade para se gerar conhecimento científico relacionado à colonização de novos ambientes criados. Tais estudos podem e devem subsidiar o manejo ambiental de ecossistemas e por conseqüência a conservação de seus integrantes.

A nova linha de costa que surge com a formação de um reservatório é estabelecida em uma superfície geológica e biologicamente não preparada para essa situação. A estrutura do solo, vegetação que o cobre e a fauna que vive naquele lugar não estão absolutamente ajustadas às áreas ribeirinhas e zonas inundáveis. Sendo ambientes instáveis, a linha da costa sofre processos de erosão e assoreamento, lixiviação e compactação, além dos relacionados com a reversão do fluxo da água das camadas freáticas. A intensidade deste fenômeno varia com os tipos de solo, a maior ou menor força das ondas, a qualidade físico-química da água e até da presença, nesta, de troncos e elementos flutuantes que impulsionados pelas ondas funcionam com aríetes contra as margens (Müller, 1995).

O impacto ambiental gerado por um reservatório de hidrelétrica é bastante relevante, uma vez que o volume de água represado altera desde o micro-clima da região até as nascentes e lençóis freáticos, assim como as diversas formações florestais, ciliares ou não, atingidas pelo represamento do rio. As barragens e o distanciamento das margens fragmentam diversas populações animais (e.g. peixes, mamíferos e répteis aquáticos ou não) além de alterar a dinâmica fluvial, causando profundas modificações

\footnotetext{
${ }^{1}$ Fonte: www.energiabrasil.gov.br
} 
nas interações de seus componentes, levando-os diversas vezes a desequilíbrios já mencionados tais como, superpopulação ou extinção.

Quelônios e botos são exemplos de animais carismáticos que devido à sua maior vulnerabilidade, contam com projetos de conservação próprios, associados muitas vezes a Organizações Não-Governamentais - ONGs e/ou órgãos ambientais oficiais. Já os crocodilianos, incluindo as espécies em foco neste trabalho, nunca foram considerados em estudos de uso de habitat ou colonização de ambientes recém criados pelo represamento de um rio. Tal fato torna o presente estudo pioneiro, principalmente na obtenção de informações sobre o uso de novos habitats formados após a construção de uma UHE, pelas espécies nativas encontradas na época da coleta de dados: C. crocodilus e P. palpebrosus.

\subsection{Uso de habitat e colonização}

As populações animais, vegetais e dos demais organismos flutuam em tamanho ao longo do tempo em função de fatores determinísticos e estocásticos (Ricklefs, 2003). Os primeiros envolvem relações diretas de causa-efeito que, de certa forma, podem ser previstas e controladas. Atividades antrópicas como grandes empreendimentos, caça, pesca, agropecuária, introdução de animais exóticos, poluição e diversas outras, podem ser classificadas como tais. Os fatores estocásticos ocorrem de modo aleatório ou ligados

a causas geofísicas ou biológicas complexas, operando além da previsão e controle humanos. Por razões práticas podemos considerá-los acidentais (secas, incêndios naturais, infestação por parasitas, entre outras).

Modificações na paisagem podem influenciar direta ou indiretamente a distribuição e abundância de espécies, alterando padrões de dispersão e sua dinâmica populacional (Verdade, 1996, Wiens, 1996, Savard et al., 2000).

Segundo a definição do dicionário Houaiss (Houaiss, 2001) colonização é o ato ou efeito de colonizar, ou seja, alastrar-se por, propagar-se, invadir. Colonização sob o prisma da ecologia de populações é definido por Parsons (1987) e Ims \& Yocooz (1997) como o estabelecimento com sucesso de uma nova população em um ambiente 
desocupado. Além da simples ocorrência em um novo habitat, é necessário que a espécie sobreviva e se mantenha neste novo ambiente e, portanto, a taxa de reprodução e de sobrevivência constituem variáveis importantes para serem consideradas nos estudos de colonização a longo prazo.

A existência de uma população fonte, onde a taxa de natalidade deverá ser maior do que a de mortalidade, e a dispersão ou migração de indivíduos, processos geralmente associados ao conceito de metapopulação (Ims \& Yoccoz, 1997), são requisitos fundamentais para que o processo de colonização ocorra. Ims \& Yoccoz (1997) salientam que o processo de colonização depende diretamente da probabilidade de encontro de um novo habitat, da distância entre habitats e da conectividade da paisagem, fatores que por sua vez refletem a distribuição espacial dos habitats.

No presente trabalho tal ambiente "desocupado" foi gerado a partir de uma drástica alteração no ambiente fluvial, resultante do represamento do Rio Tocantins para a instalação da UHE de Lajeado. A ocupação, pelos crocodilianos, dos novos sítios criados em função do represamento do rio pode ser chamado de colonização.

Para que o processo de colonização ocorra é necessário, além de um habitat com condições ideais, a existência de uma população fonte que forneça indivíduos para este ambiente desocupado. Desta forma alguns modelos metapopulacionais (fonte sumidouro) podem ser utilizados para explicar tanto processos de colonização como de extinção local (McCullough, 1996; Ims \& Yoccoz, 1997; Barbraud et al., 2003).

No presente estudo a área passível de ser colonizada (i.e. margens do reservatório) representa uma área consideravelmente maior que área ocupada pelo antigo leito do rio, o que pode implicar num primeiro momento, em aumento populacional. Somente estudos de longo prazo, considerando taxas de reprodução e sobrevivência podem fornecer informações mais precisas sobre o processo de colonização (Likens, 1989). Tendo em vista que o presente trabalho coletou informações num período de aproximadamente um ano pós represamento, o termo mais adequado ao processo ecológico de ocupação dos novos habitats será tratado aqui como uso de habitat, apesar de provavelmente estar ocorrendo colonização de espécies. 
Para uma compreensão mais detalhada tanto sobre a colonização, como uso de habitat nestes novos ambientes criados, torna-se de fundamental importância entender como se dá a ocupação do entorno do reservatório pelas espécies de crocodilianos num período próximo ao represamento. A verificação de reprodução dos crocodilianos em anos subseqüentes ao represamento indicaria, em princípio, uma adequação deste novo habitat às espécies, pressupondo assim a ocorrência do processo de colonização. 


\section{MATERIAL E MÉTODOS}

\section{1 Área de estudo}

A área de estudo localiza-se na região centro-oeste do Brasil, com ponto central no município de Palmas, Estado de Tocantins (Figura 2), aproximadamente entre os paralelos $9^{\circ} 30^{\prime} \mathrm{S}$ e $11^{\circ} 30^{\prime} \mathrm{S}$ e os meridianos $48^{\circ} 15^{\prime} \mathrm{W}$ e $48^{\circ} 45^{\prime} \mathrm{W}$. O estudo foi realizado no reservatório da UHE do Lajeado, instalada no rio Tocantins, abrangendo os municípios de Lajeado, Palmas, Porto Nacional, Brejinho de Nazaré e Ipueiras.

Através da composição colorida de duas cenas LANDSAT TM, com resolução de 30 metros, cenas 222-67 e 222-68, passagem do dia 09 de julho de 2003, obtidas junto ao INPE, foi possível caracterizar a paisagem nas proximidades do reservatório (procedimento descrito no item 3.3) (Figura 3). Tais imagens foram as mesmas utilizadas para classificação por sensoriamento remoto neste estudo. Nota-se que o entorno do reservatório é caracterizado por manchas de cerrado e por ambientes moldados por atividades antrópicas, com áreas urbanas localizadas principalmente na margem direita do rio Tocantins (Municípios de Palmas e Porto Nacional). 


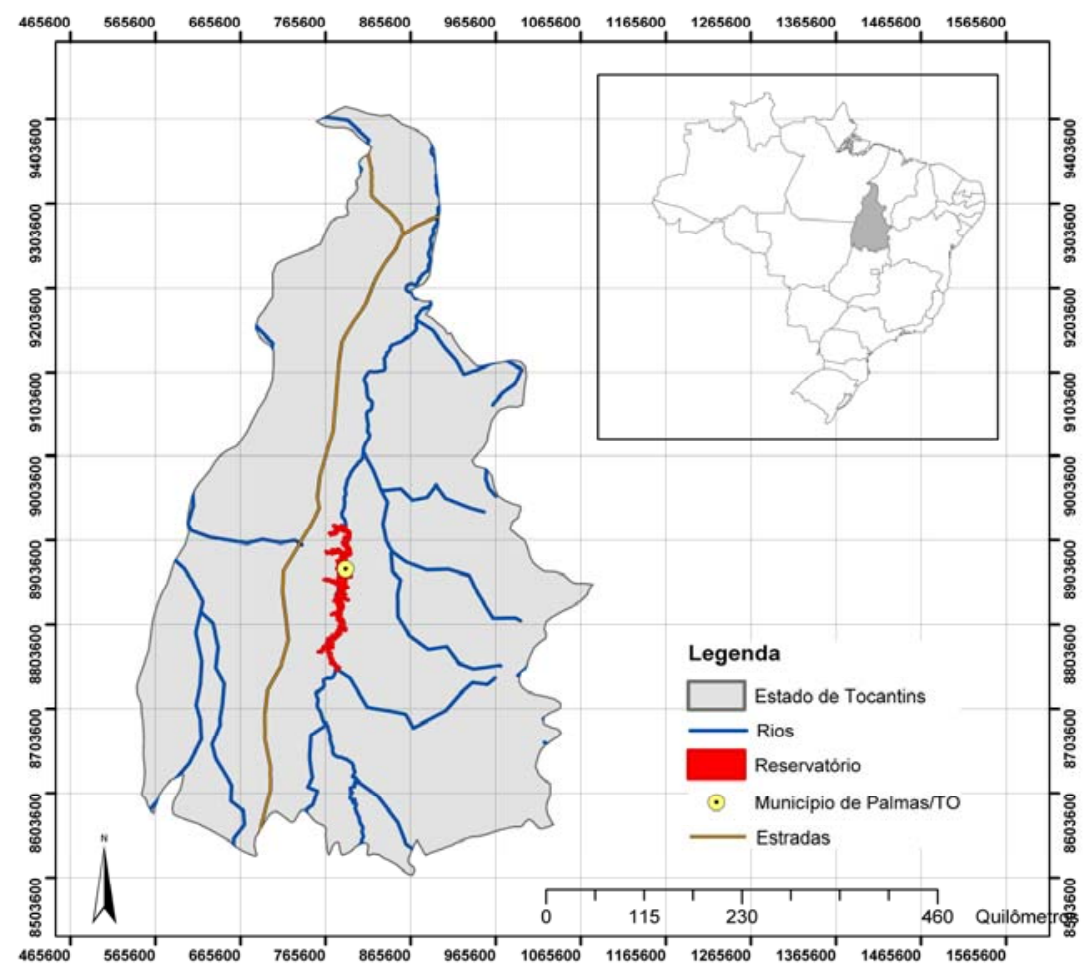

Figura 2 - Localização do reservatório da Usina Hidrelétrica de Lajeado, Estado de Tocantins

O rio Tocantins é formado a partir dos Rios das Almas e Maranhão, cujas nascentes situam-se no planalto de Goiás, Distrito Federal, região mais central do Brasil, na cota $1.100 \mathrm{~m}$. Desenvolve-se no sentido Sul - Norte percorrendo uma extensão de 2.400 km, até desaguar na Baia de Marapatá, Ilha de Marajó, próximo a Belém do Pará2

O curso do rio Tocantins pode ser dividido nos seguintes trechos: Alto Tocantins (das nascentes até a Cachoeira do Lajeado, numa extensão de $1.060 \mathrm{~km}$ e desnível de 925 m); Médio Tocantins (da Cachoeira do Lajeado até a Cachoeira de Itaboca, numa extensão de 980 km e desnível de 149 m); Baixo Tocantins (da Cachoeira de Itaboca até a foz, numa extensão de $360 \mathrm{~km}$ e desnível de $26 \mathrm{~m}$ ).

$\mathrm{Na}$ Bacia do Tocantins o bioma predominante é o Cerrado e o clima é classificado no sistema de Köppen como Aw (tropical quente). Nela estão localizadas

\footnotetext{
${ }^{2}$ http://www.simego.sectec.go.gov.br/produtos/Hidro/bacias_hidricas/bacia_do_tocantins.htm
} 
diversas Unidades de Conservação (UC) tais como os Parques Nacionais da Chapada dos Veadeiros e do Araguaia; Áreas de Proteção Ambiental de Pouso Alto, Ilha do Bananal, Serra do Lajeado; Parque Estadual do Jalapão, além de Áreas Indígenas como Parque do Araguaia, Xerente, Kraholândia, Apinayé.

Constata-se também uma nítida interferência da Bacia Amazônica no que diz respeito à biodiversidade. Um exemplo disso é o $M$. niger, tipicamente amazônico, mas com distribuição também em rios de Cerrado (Medem, 1983; Plotkin et al., 1983; Peres \& Carkeek, 1993; Brazaitis et al., 1996; Lacher \& Alho, 2001).

O Rio Tocantins, a exemplo do Rio Tietê, começa a ser transformado num grande lago dividido por barragens estrategicamente construídas (Figuras 4 e 5). Destaca-se a barragem da UHE Serra da Mesa, município de Minaçu, Goiás, responsável pelo maior reservatório de água (em volume) do Brasil com capacidade para 54,4 bilhões de $\mathrm{m}^{3}$, área de $1.784 \mathrm{~km}^{2}$, e potência instalada de $1.275 \mathrm{MW}$. Ainda em Goiás, nos limites municipais entre Minaçu e Cavalcante, está a UHE Cana Brava com capacidade de gerar $450 \mathrm{MW}$ e reservatório com área de $139 \mathrm{~km}^{2}$. A próxima grande usina já construída é justamente a UHE de Lajeado, situada a $1.030 \mathrm{~km}$ da foz, área do reservatório de $630 \mathrm{~km}^{2}$, potência instalada de $902 \mathrm{MW}$. A UHE de Tucuruí está localizada no Baixo Tocantins a $350 \mathrm{~km}$ ao Sul de Belém, seu lago ocupa $2.875 \mathrm{~km}^{2}$ e suas turbinas tem capacidade de gerar 4.240 MW. Desta forma, o Rio Tocantins contribui através de suas quatro grandes UHEs instaladas, com 6.867 MW de eletricidade, sendo que os reservatórios ocupam juntos uma área total de $5.428 \mathrm{~km}^{2}$. 


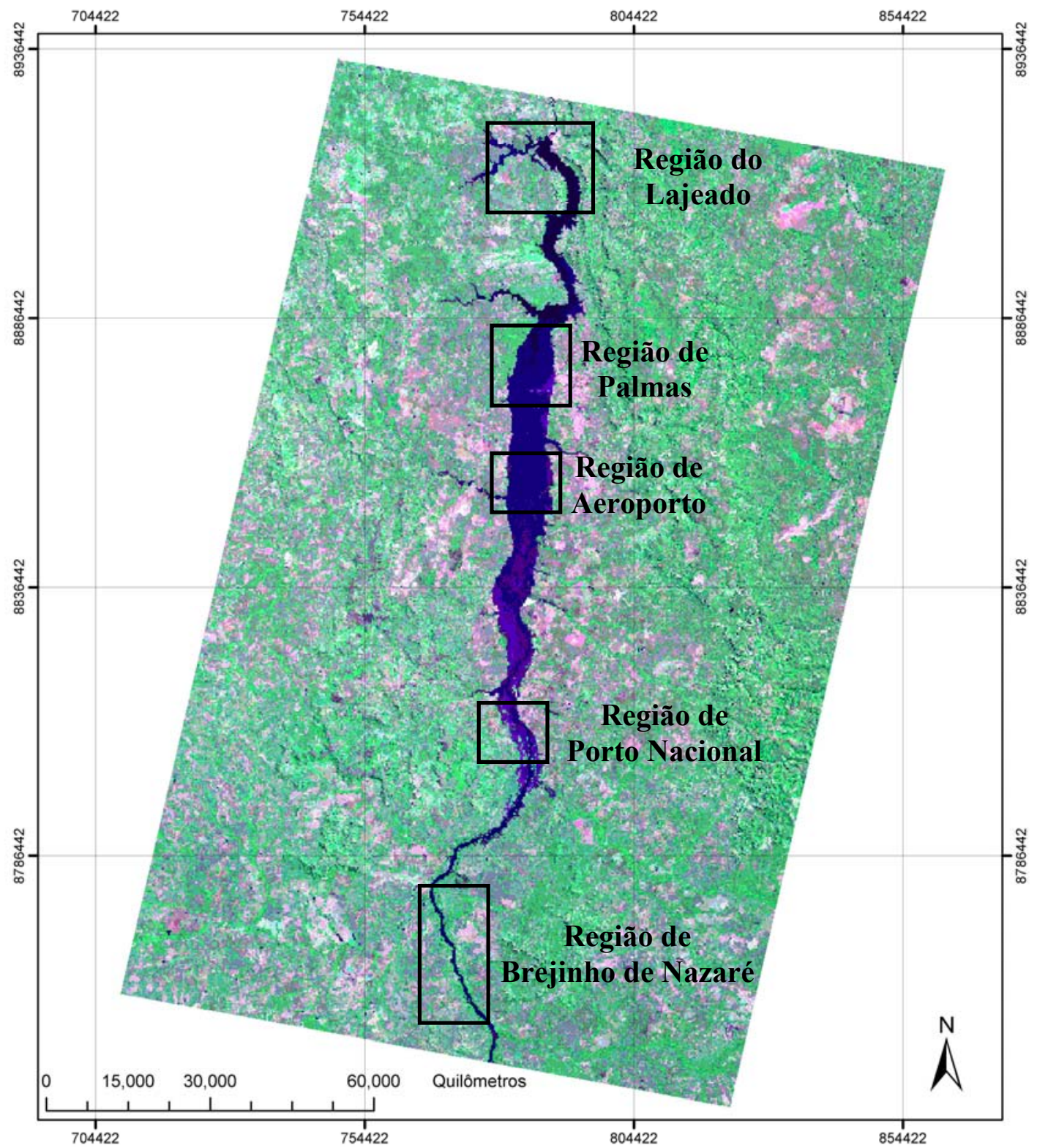

Figura 3 - Composição colorida (LANDSAT TM) das bandas 2, 3 e 4 para a área do reservatório da UHE Lajeado, TO, data de 09 de julho de 2003, indicando as cinco regiões monitoradas 


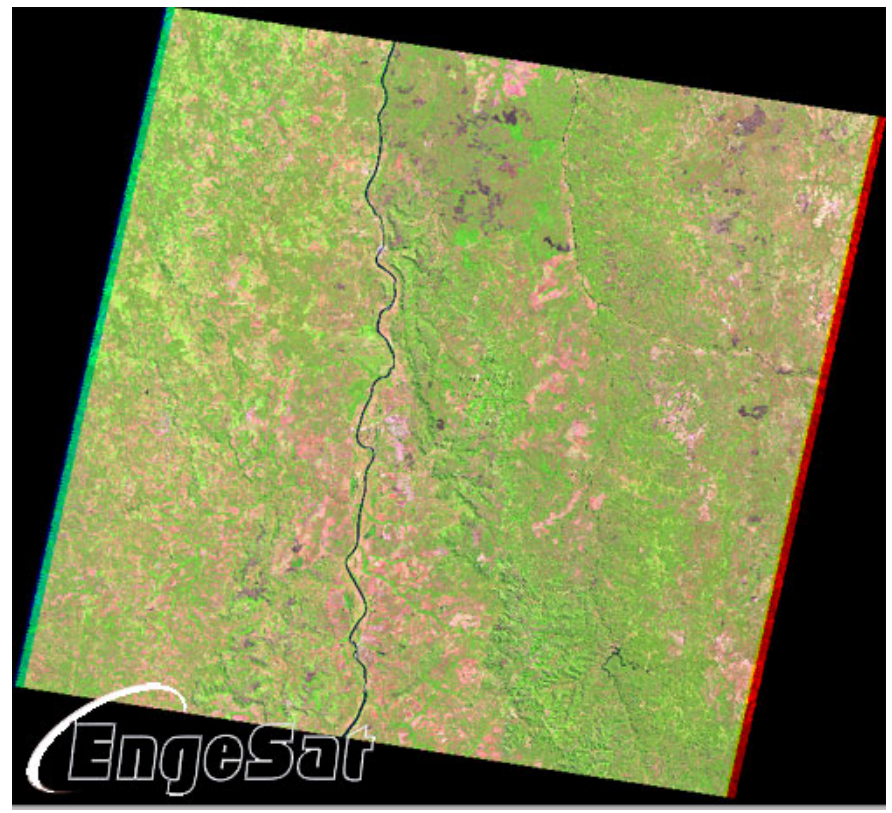

Figura 4 - Rio Tocantins na área de estudo pré-enchimento (25/06/2001) (Fonte: www.engesat.com.br)

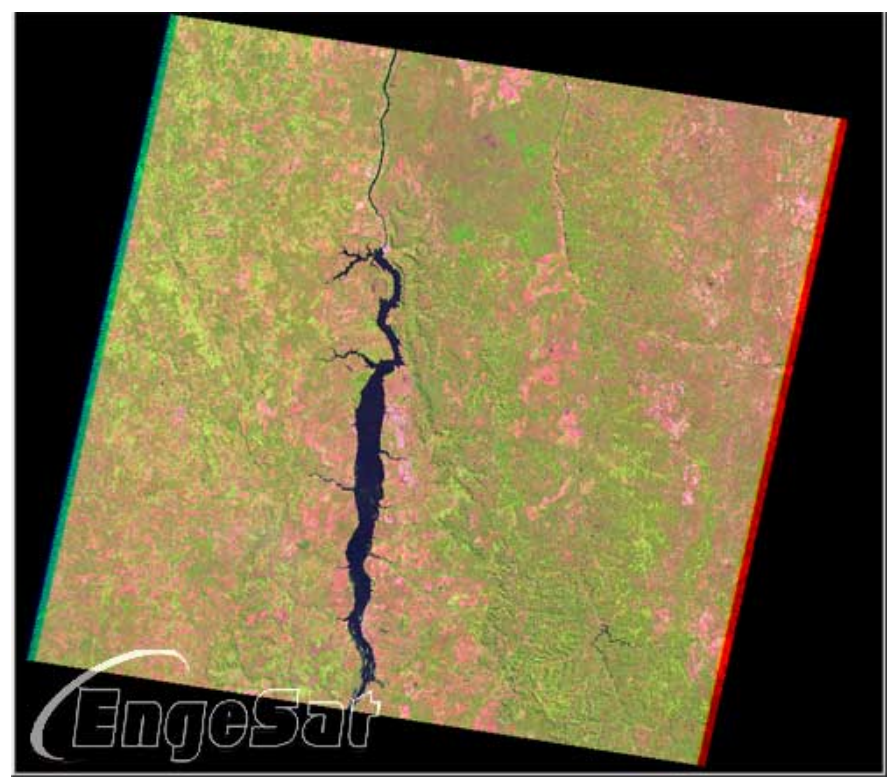

Figura 5 - Rio Tocantins na área de estudo pós-enchimento (27/05/2002) (Fonte: www.engesat.com.br) 
Além destas usinas já construídas temos ainda as UHEs Peixe Angical e São Salvador, ambas em fase de construção, e as UHEs Ipueiras, Tupiratins, Estreito, Serra Quebrada, todas no Rio Tocantins, além da UHE Santa Isabel no Rio Araguaia, em fase de projeto (Atlas do Tocantins, 1999).

Como várias destas usinas estão posicionadas em seqüência, os seus lagos estão (ou estarão) separados apenas pelas barragens, desta forma, a construção de eclusas unindo os reservatórios viabiliza a navegação em trechos outrora acidentados. A implantação de uma hidrovia através dos reservatórios de UHEs é mais um fator que pesa favoravelmente à construção de barragens em rios. O apelo econômico de um transporte mais barato para uma região em desenvolvimento agrário se mostra ainda mais forte que o apelo ambiental.

\subsection{Métodos de contagem, captura, contenção e biometria}

O presente estudo foi realizado durante o período de outubro de 2002 a julho de 2003, dividido em cinco campanhas de dez dias: outubro 2002; dezembro 2002; março 2003; maio 2003 e julho 2003. A coleta de dados foi realizada nas margens direita e esquerda ao longo do reservatório da UHE de Lajeado nos municípios de Lajeado, Palmas, Porto Nacional, Brejinho de Nazaré e Ipueiras, região central do estado do Tocantins.

Devido à grande extensão do reservatório $(170 \mathrm{~km})$ e a dificuldade de amostragem de toda área, foram definidos cinco regiões de coleta a partir de sobrevôos preliminares de helicóptero e incursões noturnas e diurnas ao reservatório. Neste levantamento preliminar foi possível, através de algumas capturas, identificar as espécies de crocodilianos ocorrentes e padronizar o método de amostragem.

O método utilizado para a localização dos animais foi o de focagem noturna à distância, seguida de aproximação e tentativa de captura (Mangini \& Nicola, 2003). Tal método é amplamente utilizado para se avaliar a abundância de crocodilianos em diferentes localidades (Herron, 1994; Da Silveira et al., 1997). 
As focagens foram realizadas nas dez regiões (considerando as margens direita e esquerda) definidas, através de incursões de 2 horas de duração em cada uma delas, com o uso de barco a motor de $25 \mathrm{Hp}$ e faróis de milha ligados a baterias de carro ou caminhão para localização dos jacarés.

Após a visualização de um animal, o barco era direcionado até o mesmo para a identificação e tentativa de captura. A aproximação final geralmente era feita a remo ou com auxílio do motor em baixa rotação. Sempre que possível os animais eram capturados e imobilizados através do uso de cambões para que fossem realizadas biometria do comprimento rostro-cloacal (SVL), e total (TTL), sexagem com auxílio de espéculo e finalmente marcação através do uso de anilhas metálicas colocadas entre os dedos do membro anterior ou posterior direito dos animais. Após estes procedimentos os animais eram soltos no local de captura.

Outros parâmetros também eram anotados após a visualização ou captura de um indivíduo: data, horário, local, região, espécie, coordenada geográfica, profundidade, margem em que foi observado, estimativa de tamanho total e da cabeça (segundo Magnusson, 1983), e microhabitat em que o animal se encontrava associado. Nos casos em que o animal fugia antes da identificação, a espécie era registrada como indeterminada. Os demais parâmetros eram anotados normalmente.

Devido às condições do reservatório, que possui uma grande quantidade de matéria vegetal submersa (árvores que não foram totalmente encobertas, formando os "paliteiros", ou ainda trechos com baixa profundidade), não foi possível manter o barco com velocidade constante durante as focagens, sendo difícil muitas vezes a aproximação das margens. Tal condição impedia a realização de estudos de densidade demográfica, considerando-se a quantidade de indivíduos por quilômetro de rio percorrido (Da Silveira et al., 1997). Desta forma, optou-se pela padronização do esforço amostral relativo ao tempo de focagem em ambas as margens do reservatório, assim como entre as diferentes regiões amostradas.

Foi realizado na primeira campanha (outubro de 2002) um sobrevôo de helicóptero a fim de detectar possíveis locais de nidificação, técnica bastante difundida 
conforme proposta por Mourão \& Magnusson (1997). A análise dos dados foi realizada através da estatística descritiva e testes de qui-quadrado (Zar, 1999).

\subsection{Classificação da imagem por meio de sensoriamento remoto}

As imagens LANDSAT TM, com resolução de 30 metros, cenas 222-67 e 22268, passagem do dia 09 de julho de 2003, obtidas junto ao INPE, foram classificadas com a finalidade de identificar agrupamentos de pixels de comportamentos espectrais semelhantes, que pudessem estar relacionados a habitats potenciais à ocorrência das espécies de jacarés.

As bandas 2, 3 e 4 correspondentes às faixas do espectro luminoso: verde $(0,52 \mu \mathrm{m}-0,60 \mu \mathrm{m})$, vermelho $(0,63 \mu \mathrm{m}-0,69 \mu \mathrm{m})$ e infravermelho próximo $(0,76 \mu \mathrm{m}-$ $0,90 \mu \mathrm{m})$, respectivamente, foram utilizadas por refletirem bem a água, o solo e a vegetação de entorno. Posteriormente, foram geradas composições coloridas para cada cena, as quais foram mosaicadas em uma única imagem para facilitar o processo de classificação.

A área do reservatório foi então isolada do restante da imagem utilizando-se uma máscara com os limites da área alagada. Este procedimento foi adotado para que a classificação fosse direcionada somente para o reservatório. A imagem obtida foi então classificada de forma não supervisionada pelo método de agrupamento e retenção de todas as classes encontradas. Por fim, aplicou-se um filtro de Moda para a eliminação de ruídos obtidos na classificação (pixels isolados).

O tratamento e classificação das imagens foram realizados com o auxílio do software IDRISI 32 (Eastman, 1999) enquanto que o processamento final e produção de mapas foi realizado com auxílio do software ArcView 3.2 (ESRI, 1996).

\subsubsection{Distribuição espacial de jacarés em relação às classes identificadas pela classificação da imagem}


Os pontos de visualização foram transferidos para o SIG ArcView com o objetivo de verificar a distribuição espacial das espécies observadas em relação às classes identificadas pelo processo de classificação. Utilizando-se uma função de estatística local no SIG, foi possível a extração do identificador de cada classe obtida e incorporação do mesmo no banco de dados de pontos coletados.

Com o banco de dados unificado, contendo as informações de campo somadas ao identificador de cada classe foi possível analisar a relação entre as variáveis coletadas e as classes obtidas por sensoriamento remoto.

A densidade de $C$. crocodilus e $P$. palpebrosus foi estimada a partir do cálculo da área de cada mancha em cada faixa amostral de $300 \mathrm{~m}$. Os limites da faixa amostral foram definidos a partir da primeira e da última visualização dentro de cada trecho, como exemplificado na Figura 6, uma vez que não existiam limites geográficos definindo os trechos. A utilização da primeira e da última visualização para determinar a faixa amostral corresponde ao início e fim das duas horas de focagem realizadas nas regiões monitoradas nas cinco campanhas (margem direita e esquerda) evitando assim a superestimação dos dados. 


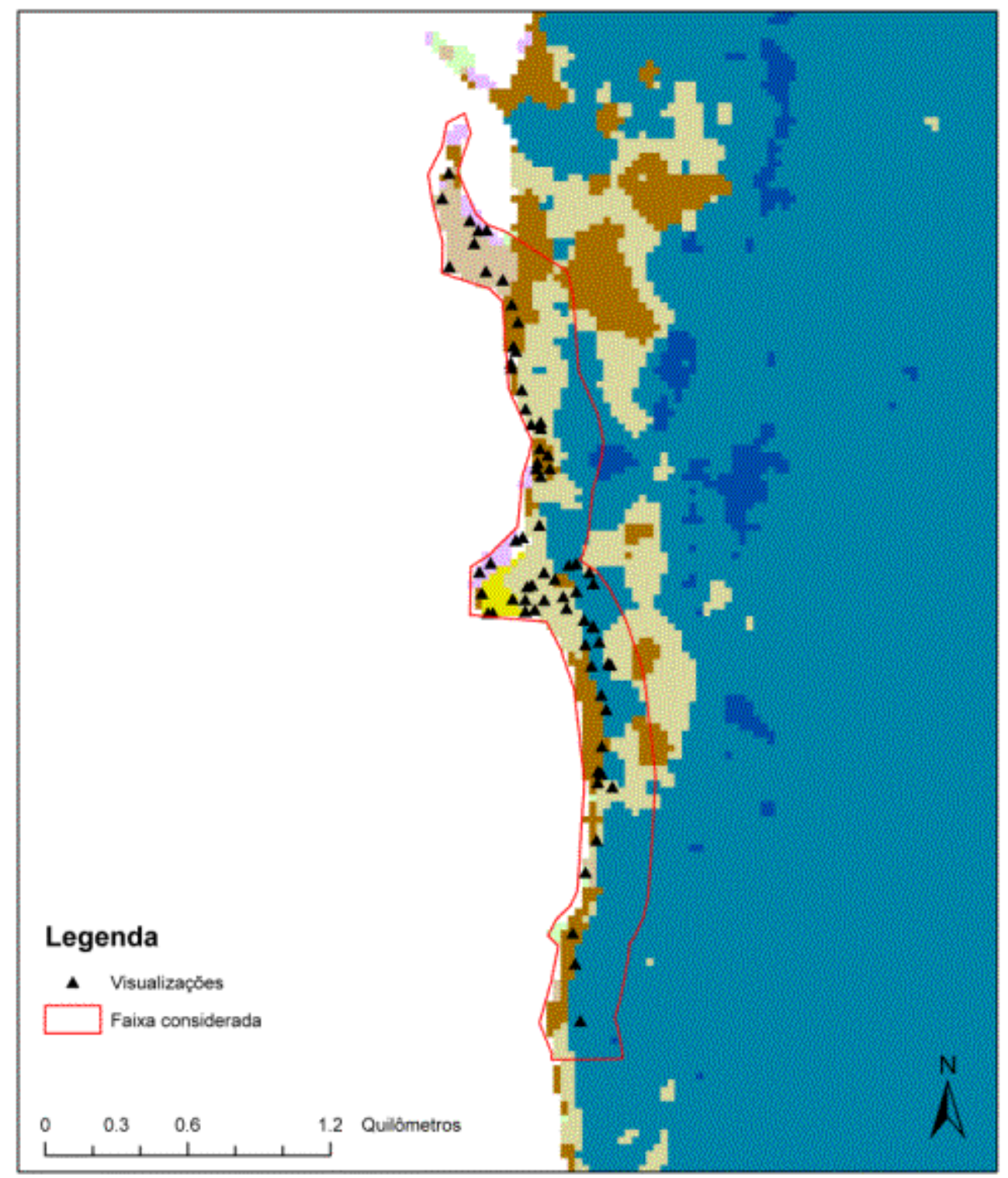

Figura 6 - Exemplo da faixa amostral considerada para o cálculo da área de cada mancha de habitat 


\section{RESULTADOS}

\subsection{Abundância, taxa entre os sexos e distribuição pseudo-etária}

Foram observados, durante as cinco campanhas realizadas neste estudo, 659 jacarés. Dos indivíduos observados, 259 (39,30\%) foram identificados como $C$. crocodilus, $102(15,48 \%)$ como P. palpebrosus e 298 (45,22\%) como indeterminados (Figura 7). Não foi observado M. niger durante o estudo. Os filhotes observados e capturados nos agrupamentos não foram considerados no estudo por enviesarem o resultado, sendo analisados separadamente.

O número de indivíduos, para ambas espécies somados os indeterminados, observados durante as cinco campanhas foram: 162, 128, 129, 116 e 124 respectivamente (média 131,80 $\pm 17,64$ ), sendo que tais valores não diferem

significativamente $\left(\chi^{2}=9.44 ; \mathrm{gl}=4 ; \mathrm{p}=0.050\right)$. As campanhas foram realizadas ao longo de 10 meses (outubro 2002 a julho 2003) abrangendo tanto a estação seca como chuvosa. A Figura 8 mostra o número de $C$. crocodilus, P. palpebrosus e indeterminados ao longo das cinco campanhas. 


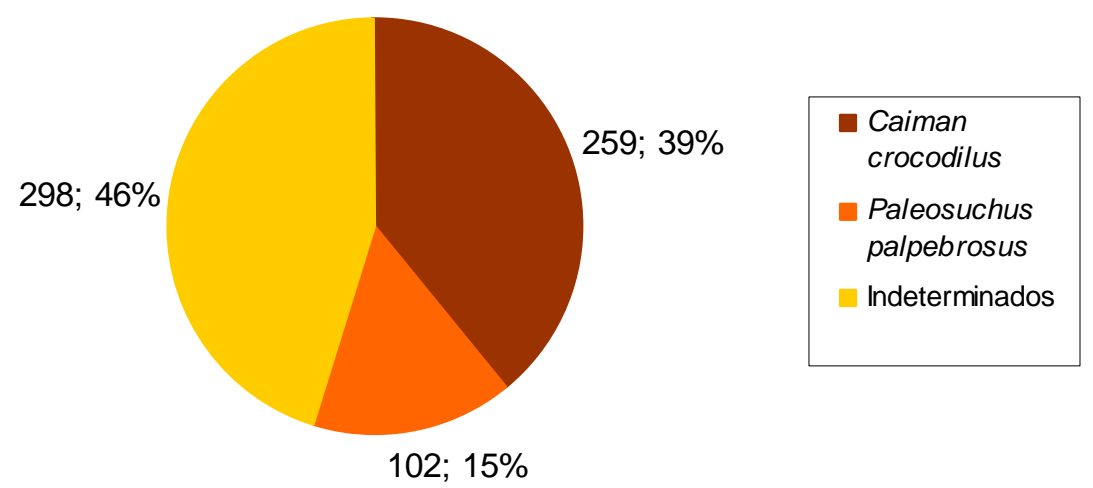

Figura 7 - Freqüência absoluta e freqüência relativa (\%) para cada espécie e indeterminados, somadas as cinco campanhas

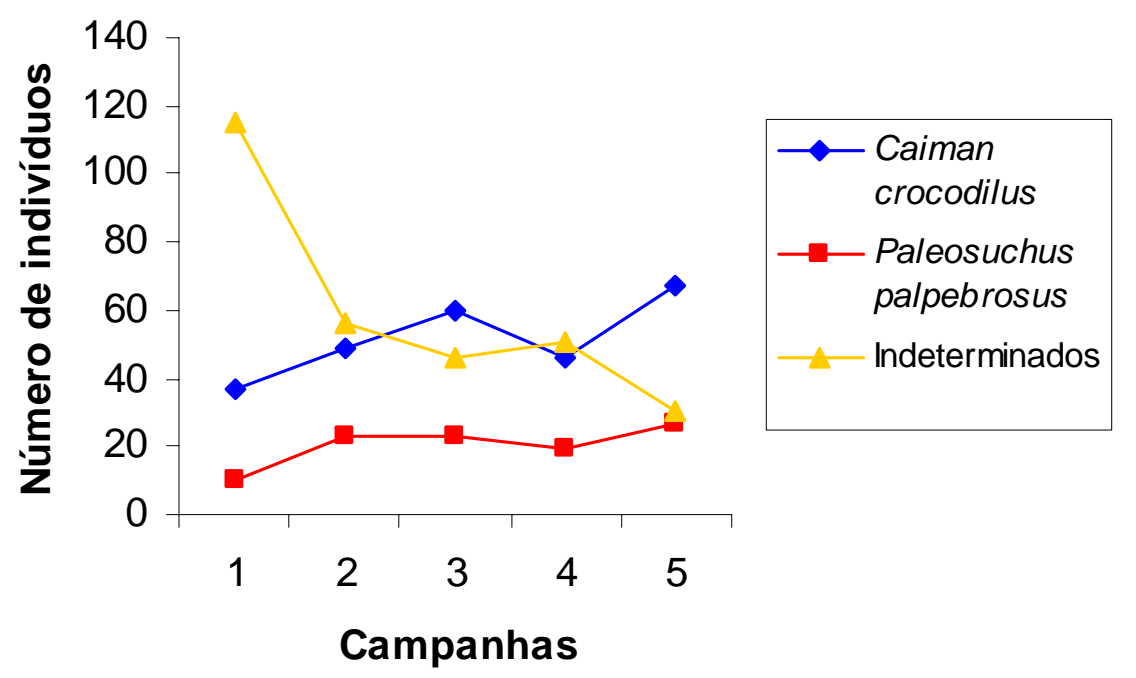

Figura 8 - Número de animais observados (excluindo os filhotes), para as espécies $C$. crocodilus, $P$. palpebrosus e indeterminados no reservatório da UHE de Lajeado, TO, em cada campanha

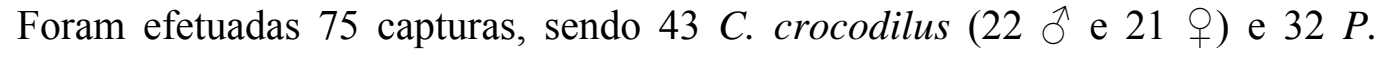
palpebrosus (22 $\sigma^{\lambda}$ e 10 + ). A razão sexual foi de 1:1 em C. crocodilus $\left(\chi^{2}=0,023, \mathrm{gl}=1\right.$, $\mathrm{p}>0,05)$ e $2: 1$ em $P$. palpebrosus $\left(\chi^{2}=0,063, \mathrm{gl}=1, \mathrm{p}>0,05\right)$, machos e fêmeas 
respectivamente. A eficiência de captura foi de 16,60\% para C. crocodilus, 31,37\% para P. palpebrosus e $11,38 \%$ para ambas as espécies considerando também os indeterminados (Tabelas 1 e 2). A captura de exemplares de P. palpebrosus foi mais eficiente se comparada à de $C$. crocodilus $\left(\chi^{2}=6.06 ; \mathrm{gl}=1 ; \mathrm{p}=0.013\right)$.

Tabela 1. Número de indivíduos identificados e indeterminados quanto à espécie, em cada campanha realizada (valores gerais por espécie e sem os filhotes)

\begin{tabular}{cccccc}
\hline Campanha & $\begin{array}{c}\text { Caiman } \\
\text { crocodilus }\end{array}$ & $\begin{array}{c}\text { Paleosuchus } \\
\text { palpebrosus }\end{array}$ & Identificados & Indeterminados & n \\
\hline 1 (out/02) & 37 & 10 & 47 & 115 & 162 \\
$2(\mathrm{dez} / 02)$ & 49 & 23 & 72 & 56 & 128 \\
$3(\mathrm{mar} / 03)$ & 60 & 23 & 83 & 46 & 129 \\
4 (mai/03) & 46 & 19 & 65 & 51 & 116 \\
5 (jul/03) & 67 & 27 & 94 & 30 & 124 \\
Total & 259 & 102 & 361 & 298 & 659 \\
Capturados & 43 & 32 & 75 & 0 & 75 \\
Eficiência de captura (\%) & 16,60 & 31,37 & 20,78 & & 11,38 \\
\hline
\end{tabular}

Tabela 2. Distribuição entre os sexos de C. crocodilus e P. palpebrosus capturados

\begin{tabular}{cccc}
\hline Espécie & Fêmeas - $q$ & Machos - $\hat{O}$ & Total \\
\hline Caiman crocodilus & $21(48,83 \%)$ & $22(51,16 \%)$ & 43 \\
Paleosuchus palpebrosus & $10(31,25 \%)$ & $22(68,75 \%)$ & 32 \\
\hline
\end{tabular}

Os dados biométricos relativos ao comprimento rostro-cloacal, "snout-vent length" (SVL), para ambas as espécies, foram distribuídos em quatro classes de tamanho (Tabela 3) conforme proposto por Ayarzagüena (1983) para C. crocodilus. 
Tabela 3. Distribuição das espécies em classes de tamanho conforme proposto por Ayarzagüena (1983) para C. crocodilus: Classe I - $\mathrm{x}<200$; Classe II $200<x<599$; Classe III - 600 $<x<899$ e Classe IV $-900<x$ (valores em mm)

\begin{tabular}{|c|c|c|c|c|c|c|c|c|}
\hline \multirow{2}{*}{ Campanha } & \multicolumn{4}{|c|}{ Caiman crocodilus } & \multicolumn{4}{|c|}{ Paleosuchus palpebrosus } \\
\hline & \multicolumn{8}{|c|}{ Classe I Classe II Classe III Classe IV Classe I Classe II Classe III Classe IV } \\
\hline $1($ out $/ 02)$ & \multicolumn{4}{|c|}{ Não medidos } & \multicolumn{4}{|c|}{ Não medidos } \\
\hline $2(\mathrm{dez} / 02)$ & 0 & 11 & 2 & 0 & 0 & 6 & 0 & 0 \\
\hline $3(\mathrm{mar} / 03)$ & 19 & 10 & 1 & 0 & 0 & 3 & 1 & 0 \\
\hline $4(\mathrm{mai} / 03)$ & 5 & 1 & 1 & 2 & 0 & 6 & 2 & 0 \\
\hline $5(\mathrm{jul} / 03)$ & 0 & 12 & 3 & 0 & 3 & 10 & 4 & 0 \\
\hline Total (classe) & 24 & 34 & 7 & 2 & 3 & 25 & 7 & 0 \\
\hline Total (espécie) & \multicolumn{4}{|c|}{67} & \multicolumn{4}{|c|}{35} \\
\hline
\end{tabular}

Não foram encontrados $P$. palpebrosus da classe IV confirmando a rara existência de animais desta espécie com este tamanho. Houve diferenças significativas entre as espécies quanto à distribuição das classes de tamanho I a III $\left(\chi^{2}=9,567, \mathrm{gl}=2\right.$, $\mathrm{p}=0,008)$ havendo um número significativamente maior de filhotes de C. crocodilus. Quando comparadas apenas a distribuição das classes II e III, não houve diferença significativa $\left(\chi^{2}=0,851, \mathrm{gl}=1, \mathrm{p}=0,356\right)$.

\subsection{Filhotes}

Foram capturados 29 filhotes no total das cinco campanhas, sendo $26 C$. crocodilus e 3 P. palpebrosus. Os primeiros foram observados em três agrupamentos, sendo o primeiro na região do Aeroporto (margem direita), o segundo no córrego Capivara (margem esquerda) e o terceiro no córrego Santa Luzia (margem esquerda).

$\mathrm{O}$ agrupamento da região do Aeroporto, encontrado pela primeira vez na terceira campanha (março de 2003), também foi observado nas quarta (maio de 2003) e quinta campanhas (julho de 2003), estando exatamente no mesmo local. A margem se 
caracterizava por ser um pasto abandonado (campo sujo) situado ao lado de um buritizal alagado e morto, representado na composição colorida pela mancha 1 . Na terceira campanha neste agrupamento onze filhotes foram capturados $(28,77 \pm 1,37 \mathrm{~cm}$ e $13,73 \pm$ 0,61 cm, médias para TTL e SVL, respectivamente). Quatro filhotes $(34,25 \pm 1,71 \mathrm{~cm}$ e 17,00 \pm 0,82 cm, médias para TTL e SVL, respectivamente) nesta mesma região foram capturados na quarta campanha, e apenas um $(33 \mathrm{~cm}$ e $14 \mathrm{~cm}$, médias para TTL e SVL, respectivamente) na quinta e última campanha.

Foram capturados oito filhotes de C. crocodilus da região do córrego Capivara $(28,44 \pm 1,68 \mathrm{~cm}$ e $13,56 \pm 0,94 \mathrm{~cm}$, médias para TTL e SVL, respectivamente), durante a campanha três, não sendo encontrado nas demais campanhas. No agrupamento do córrego Santa Luzia foram capturados dois filhotes $(32,00 \pm 1,41 \mathrm{~cm}$ e 14,00 $\pm 0,00 \mathrm{~cm}$, médias para TTL e SVL, respectivamente). Esta região foi percorrida somente durante a campanha três em uma saída de campo extra à coleta de dados.

$\mathrm{Na}$ quinta campanha (julho de 2003) foram capturados na margem de cerrado três filhotes de $P$. palpebrosus na região do Lajeado $(26,17 \pm 0,76 \mathrm{~cm}$ e $13,67 \pm 0,58$, médias para TTL e SVL, respectivamente). Estes foram os únicos filhotes observados desta espécie em todo período de estudo.

\subsection{Descrição dos habitats ocupados pelos jacarés}

Através do processo de classificação da imagem de satélite, foram identificadas 46 classes diferenciadas na área do reservatório, sendo que apenas oito destas foram consideradas na análise dos dados, representando $93 \%$ da área do reservatório. As demais classes foram descartadas da análise por apresentarem tamanho reduzido $(<2 \%$ da área total) e por apresentarem baixo número de indivíduos registrados $(<2 \%$ do total observado) A exceção para esta regra de exclusão foi a mancha 1 que, devido à alta densidade de animais, não pode ser descartada da análise apesar de sua área representar apenas $0,01 \%$ da área total (Tabela 5). 
Tabela 4. Relação das classes identificadas e o número de animais observados (excluindo os filhotes)

\begin{tabular}{cccc}
\hline Classes & Observação & $\begin{array}{c}\text { Número de } \\
\text { indivíduos }\end{array}$ & $\begin{array}{c}\text { Freqüência } \\
\text { relativa (\%) }\end{array}$ \\
\hline $\begin{array}{c}1,2,3,5,6,7,8 \text { e } 9 \\
\text { Outras }(\mathrm{n}=38)\end{array}$ & Classes consideradas & 509 & 82,51 \\
0 & Classes não consideradas & 25 & 15,4 \\
\hline Total & Fora do limite do reservatório & 125 & 2,09 \\
\hline
\end{tabular}

A distribuição espacial de C. crocodilus e P. palpebrosus em função das classes obtidas está ilustrada na Figura 9. Nota-se na figura variações de coloração nas áreas alagadas, denominadas classes, obtidas pelo método de classificação não supervisionado. Tais classes foram denominadas neste estudo como manchas de habitat aquático. Mancha é definida como um elemento da paisagem, relativamente homogêneo, que difere do seu entorno (Freemark et al., 2002). A descrição das manchas de habitat só seria possível através da identificação destes elementos em checagens de campo, que não foram realizadas após a classificação das imagens. No entanto, foi realizada uma interpretação especulativa destas manchas, reunindo as anotações de campo, a composição colorida das cenas, e os padrões de distribuição destas manchas em relação às margens, tributários e outros elementos da paisagem.

As Figuras 10, 11, 12, 13 e 14 mostram a distribuição espacial das espécies visualizadas em cada região monitorada definida neste estudo. A Figura 15 mostra em detalhe o buritizal da região do aeroporto correspondente à mancha 1 . 


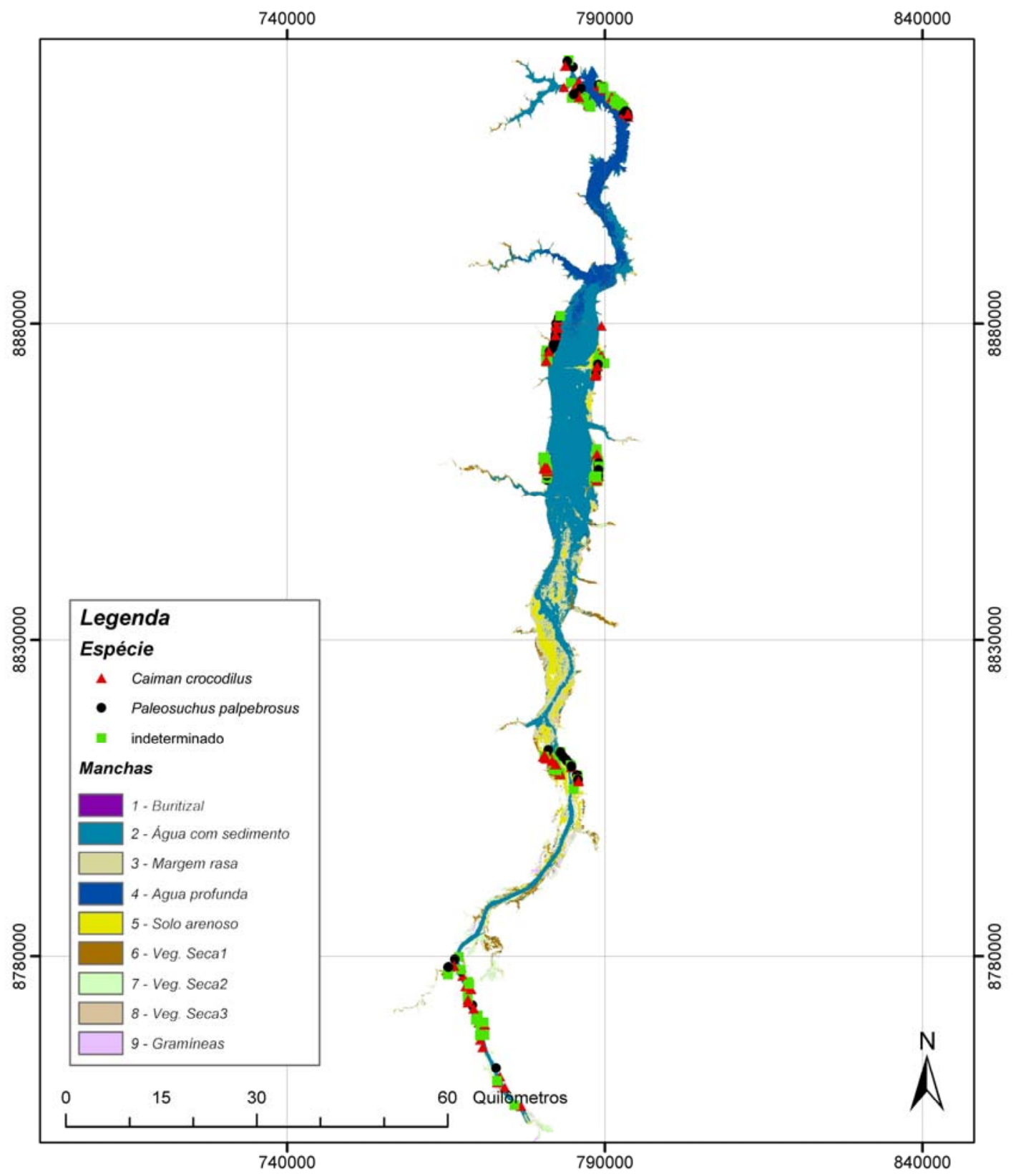

Figura 9 - Distribuição das espécies de crocodilianos nas diferentes manchas de habitat do Reservatório de Lajeado, TO 


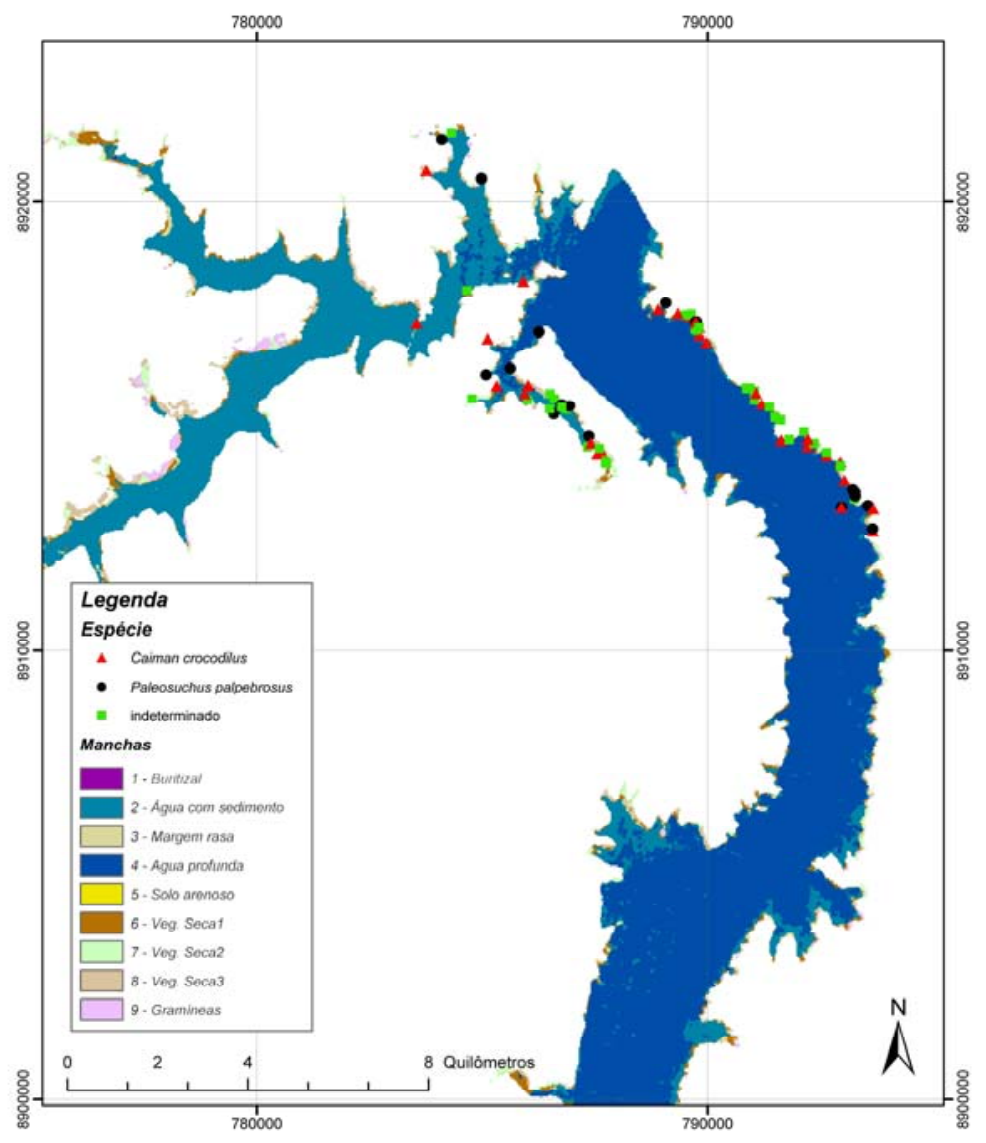

Figura 10 - Distribuição das espécies de crocodilianos nas manchas de habitat da Região do Lajeado, no Reservatório de Lajeado, TO

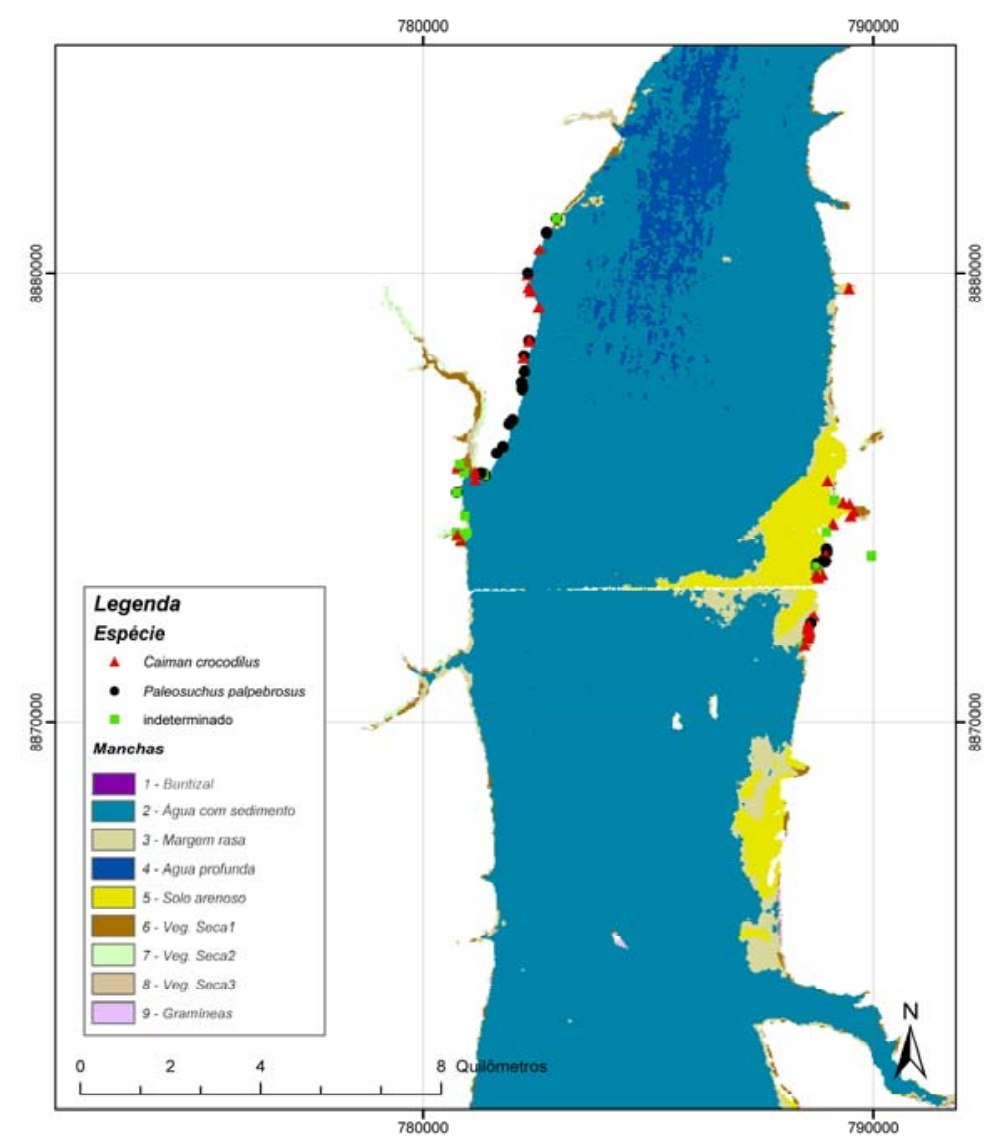

Figura 11 - Distribuição das espécies de crocodilianos nas manchas de habitat da Região do Palmas, no Reservatório de Lajeado, TO 


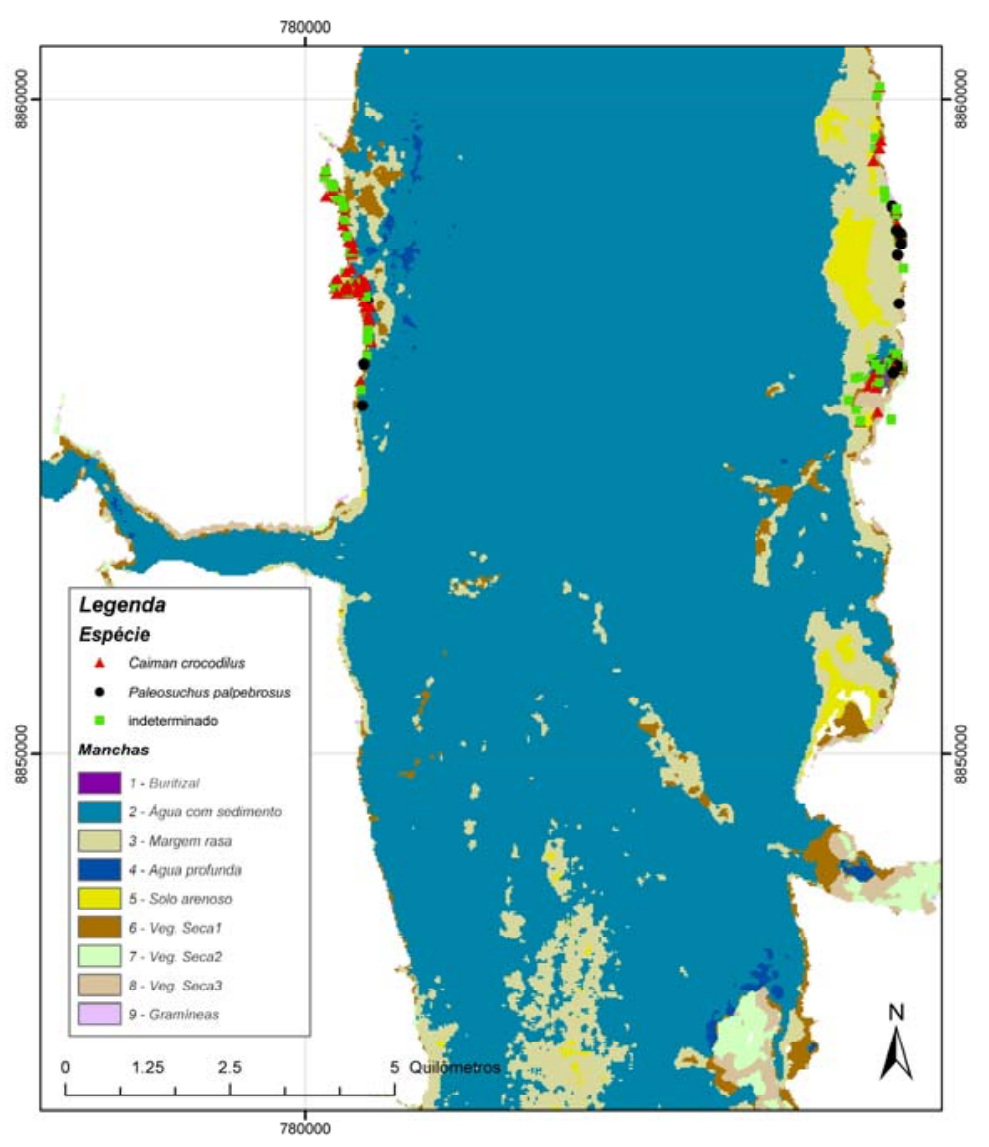

Figura 12 - Distribuição das espécies de crocodilianos nas manchas de habitat da Região do Aeroporto, no Reservatório de Lajeado, TO

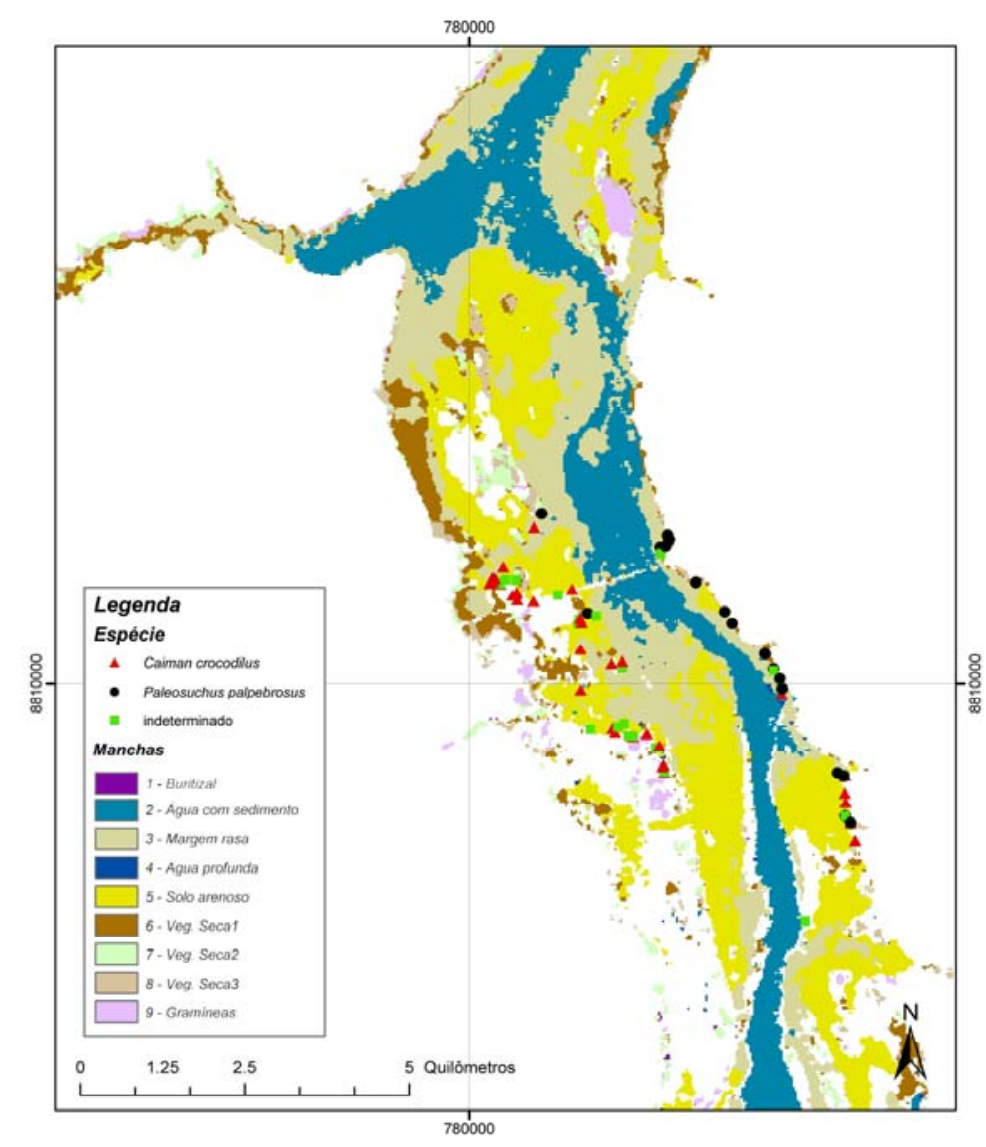

Figura 13 - Distribuição das espécies de crocodilianos nas manchas de habitat da Região de Porto Nacional, no Reservatório de Lajeado, TO 


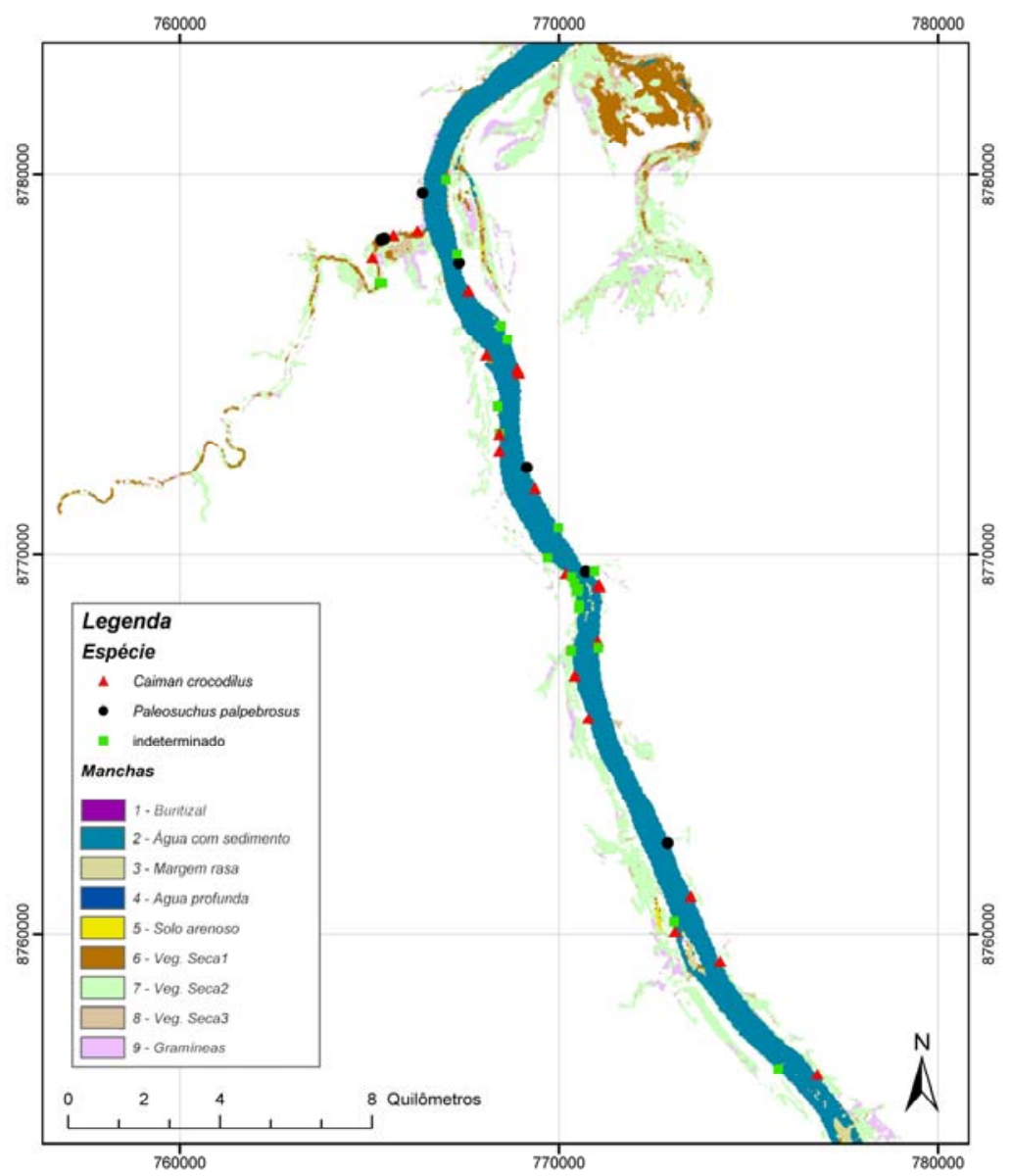

Figura 14 - Distribuição das espécies de crocodilianos nas manchas de habitat da Região de Brejinho de Nazaré, no Reservatório de Lajeado, TO

A Tabela 5 mostra o tamanho total das manchas de habitat consideradas e o tamanho das manchas de habitat amostradas no levantamento, a abundância ( $\mathrm{n}^{\mathrm{o}}$. de indivíduos) e a densidade $\left(\mathrm{n}^{\mathrm{o}}\right.$. de ind. $\left./ \mathrm{km}^{2}\right)$ de C. crocodilus e P. palpebrosus por mancha de habitat amostrado. Nota-se que C. crocodilus foi mais abundante que $P$. palpebrosus em quase todas as manchas de habitat, com exceções para as manchas 1 e 7 .

As manchas mais abundantes para C. crocodilus foram respectivamente 3, 6, 2 e 5. Para P. palpebrosus as manchas apresentam uma abundância relativamente homogênea, com exceção na mancha 9. 


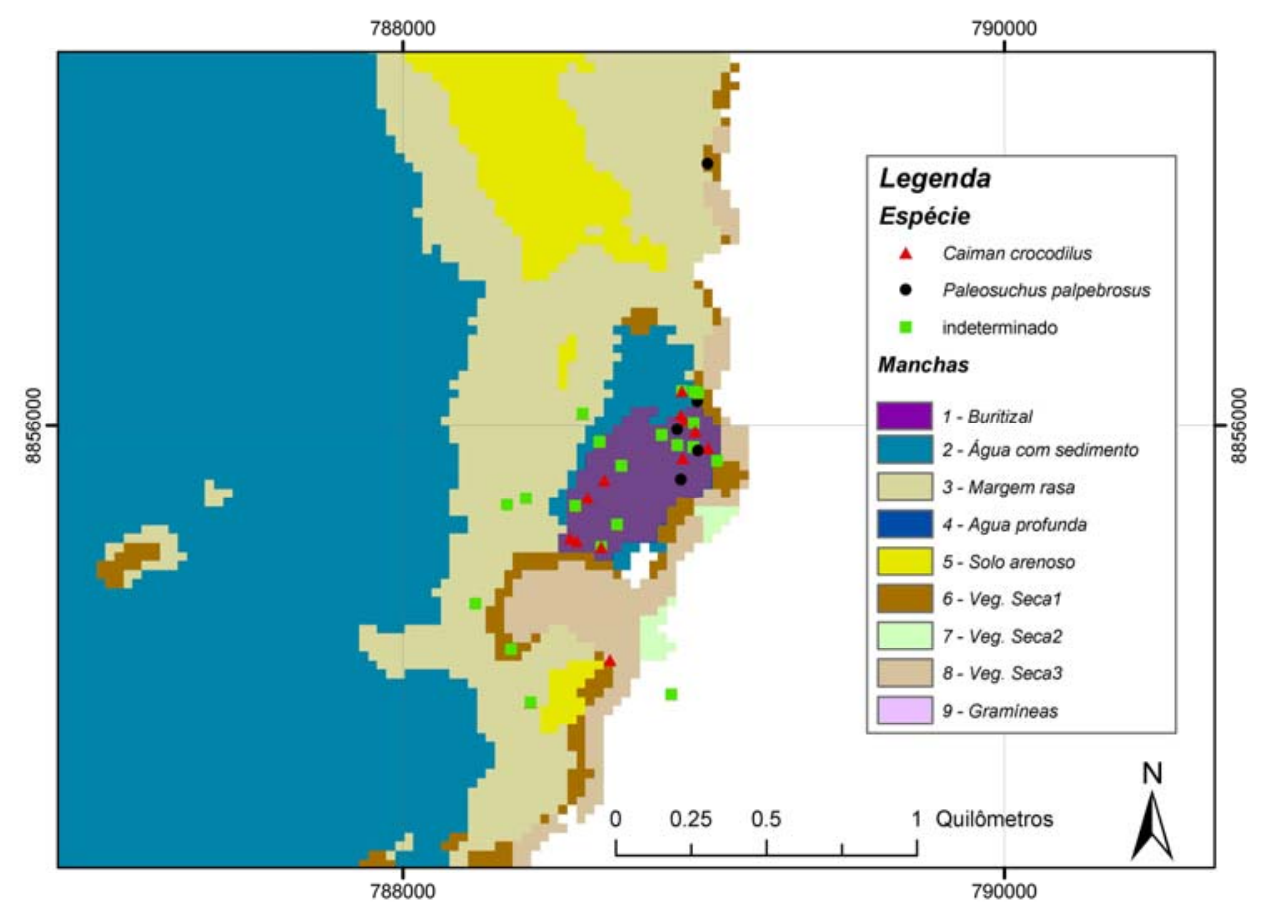

Figura 15 - Distribuição das espécies de crocodilianos nas manchas de habitat da Região do Aeroporto, margem direita. Verificar ocorrências na mancha 1 correspondente ao buritizal

Quanto à densidade, C. crocodilus foi mais freqüente que $P$. palpebrosus em quase todas as manchas, novamente as exceções foram as manchas 1 e 7 . As maiores densidades tanto de C. crocodilus como P. palpebrosus foram verificadas na mancha 1 , 60 ind. $/ \mathrm{km}^{2}$ e 110 ind. $/ \mathrm{km}^{2}$, respectivamente (Figura 16). 
Tabela 5. Área total e amostrada $\left(\mathrm{km}^{2}\right)$ das manchas de habitat aquático classificadas, abundância ( $\mathrm{n}^{\mathrm{o}}$. de ind.) e densidade (ind. $/ \mathrm{km}^{2}$ ) de cada espécie e total de crocodilianos (somados os indeterminados) por mancha de habitat amostrado. Manchas: 1) Buritizal; 2) água com sedimento; 3) margem rasa; 5) solo arenoso; 6) vegetação seca 1 ; 7) vegetação seca 2 ; 8) vegetação seca 3; e 9) gramíneas

\begin{tabular}{|c|c|c|c|c|c|c|c|c|}
\hline \multirow[b]{2}{*}{ Mancha } & \multirow{2}{*}{$\begin{array}{l}\text { Área } \\
\text { total } \\
\left(\mathrm{Km}^{2}\right)\end{array}$} & \multirow{2}{*}{$\begin{array}{c}\text { Área } \\
\text { amostrada } \\
\left(\mathbf{K m}^{2}\right)\end{array}$} & \multicolumn{3}{|c|}{ Abundância (nº de ind.) } & \multicolumn{3}{|c|}{ Densidade (ind./ $\mathbf{k m}^{2}$ ) } \\
\hline & & & $\begin{array}{c}\text { Caiman } \\
\text { crocodilus }\end{array}$ & $\begin{array}{l}\text { Paleosuchus } \\
\text { palpebrosus }\end{array}$ & Total & $\begin{array}{c}\text { Caiman } \\
\text { crocodilus }\end{array}$ & $\begin{array}{l}\text { Paleosuchus } \\
\text { palpebrosus }\end{array}$ & Total \\
\hline 1 & 0,2 & 0,1 & 6 & 11 & 17 & 60,00 & 110,00 & 330,00 \\
\hline 2 & 400,2 & 24,3 & 31 & 12 & 43 & 1,28 & 0,49 & 2,96 \\
\hline 3 & 96,0 & 4,4 & 56 & 11 & 67 & 12,84 & 2,52 & 22,69 \\
\hline 5 & 96,9 & 3,7 & 30 & 13 & 43 & 8,13 & 3,52 & 27,63 \\
\hline 6 & 58,9 & 2,0 & 36 & 10 & 46 & 18,40 & 5,11 & 39,35 \\
\hline 7 & 39,3 & 7,6 & 8 & 11 & 19 & 1,05 & 1,44 & 4,47 \\
\hline 8 & 39,7 & 1,9 & 15 & 10 & 25 & 8,10 & 5,40 & 30,76 \\
\hline 9 & 20,7 & 1,3 & 15 & 2 & 17 & 11,71 & 1,56 & 27,33 \\
\hline
\end{tabular}




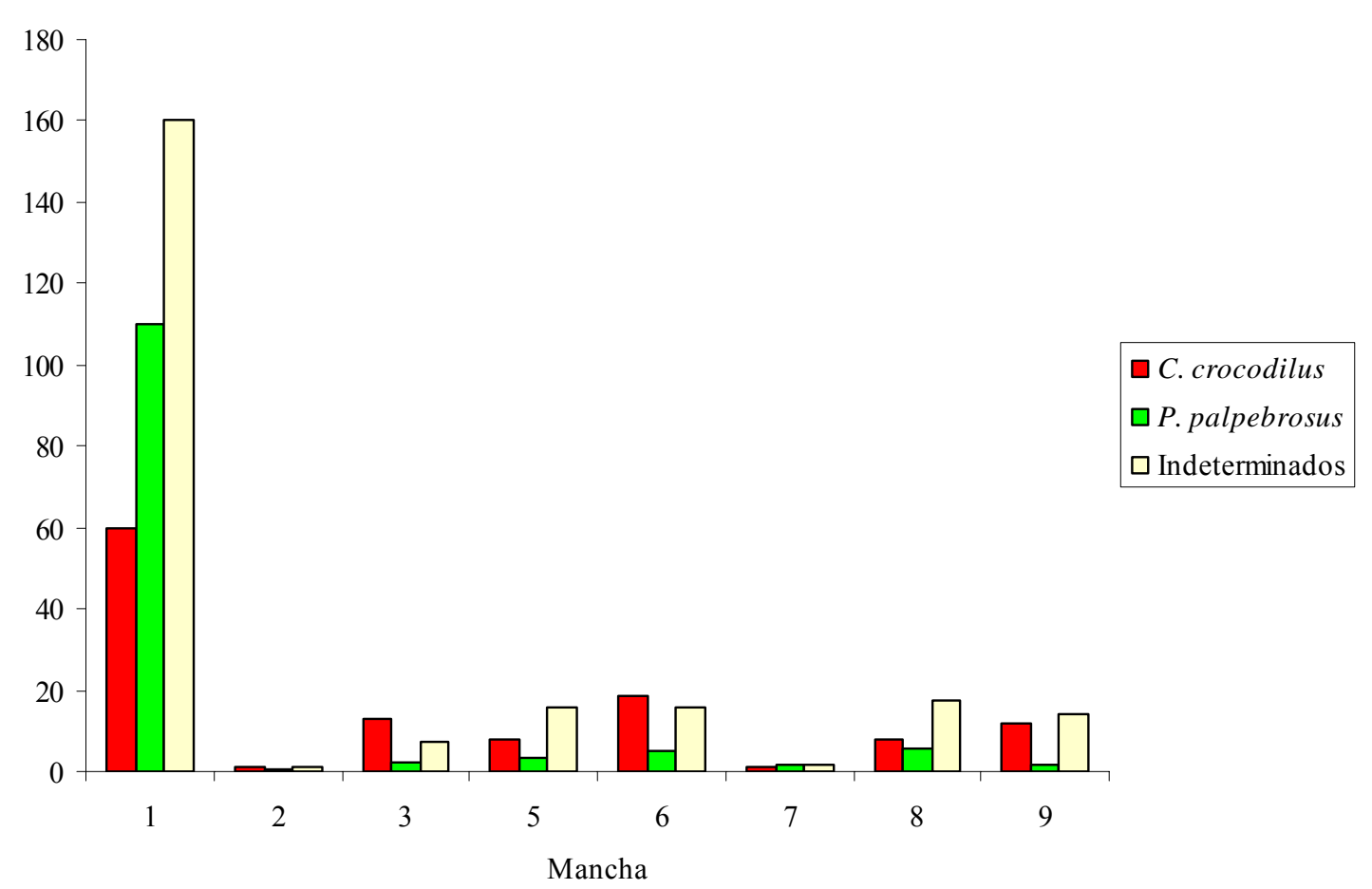

Figura 16 - Densidade para C. crocodilus, P. palpebrosus e indeterminados nas manchas classificadas

A Figura 17 apresenta o número de visualizações de crocodilianos por campanha e mancha independente da espécie. A mancha 1 (buritizal) e 2 (água com sedimentos) não apresentaram grandes oscilações ao longo do estudo, sendo importante ressaltar a pequena área ocupada pela mancha 1. A mancha 3 (margem rasa), apesar de oscilações, demonstra um aumento no número de visualizações ao longo das campanhas, ocorrendo entretanto um baixo número das mesmas na campanha 2. A mancha 5 (solo arenoso) apresenta na primeira campanha um alto número de visualizações, diminuindo bruscamente e variando pouco nas subseqüentes. A mancha 6 (vegetação seca 1) não apresenta padrão aparente de crescimento ou redução de ocorrências. A mancha 7 (vegetação seca 2) cujo início apresentou número reduzido de visualizações, demonstra relativo crescimento e tendência à estabilidade de ocorrências. A mancha 8 (vegetação 
seca 3) e mancha 9 (gramíneas) são manchas com tendência aparente à redução do número de visualizações ao longo do estudo.

A figura 18 apresenta a freqüência relativa para as mesmas variáveis da figura 16. A mancha 1 não apresenta grandes oscilações, relembrando a pequena área ocupada por tal habitat. As manchas 2, 3 e 7 aparentemente demonstram crescimento da freqüência relativa, as manchas 8 e 9 aparentemente demonstram redução e as manchas 5 e 6 tendem a uma certa oscilação desta variável analisada.

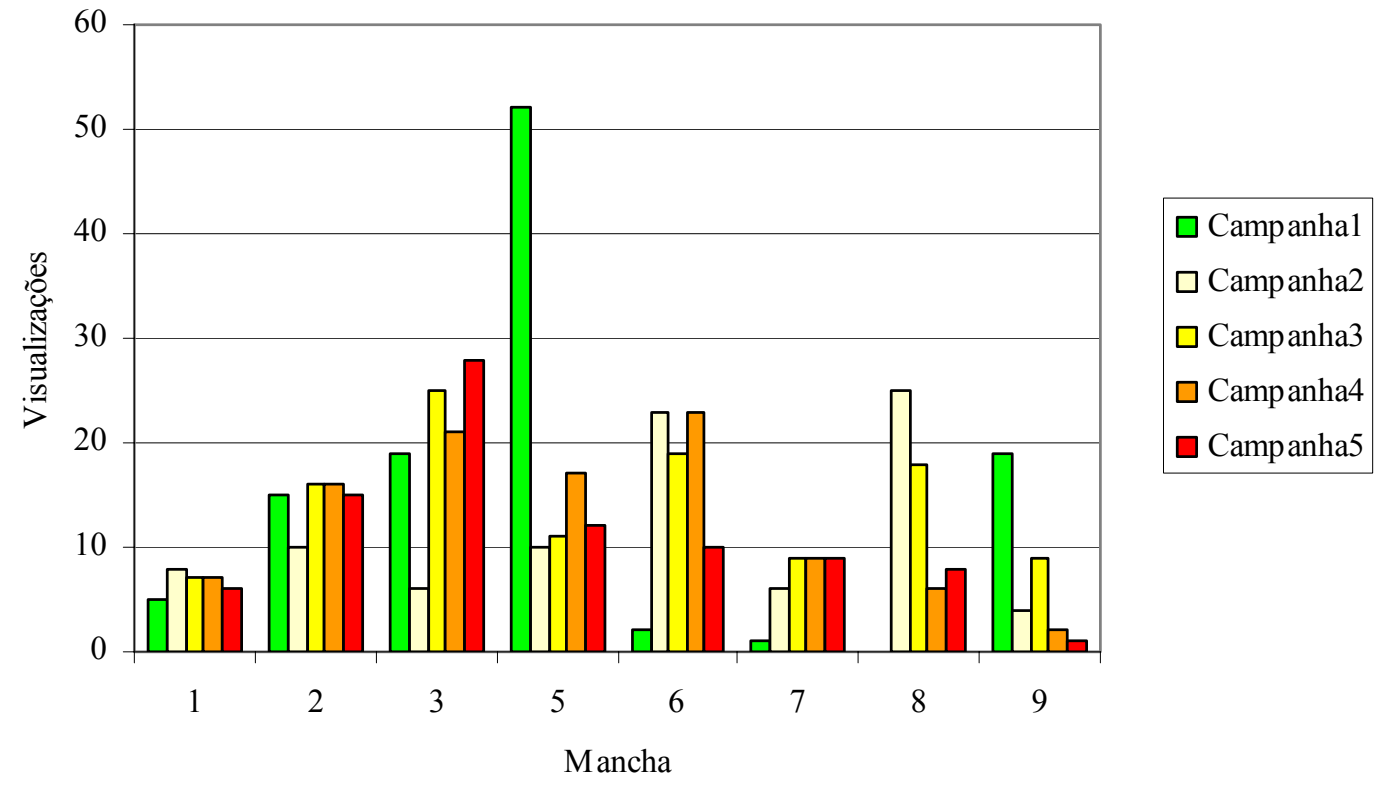

Figura 17 - Número de visualizações de crocodilianos, por campanha, em cada mancha de habitat definida 


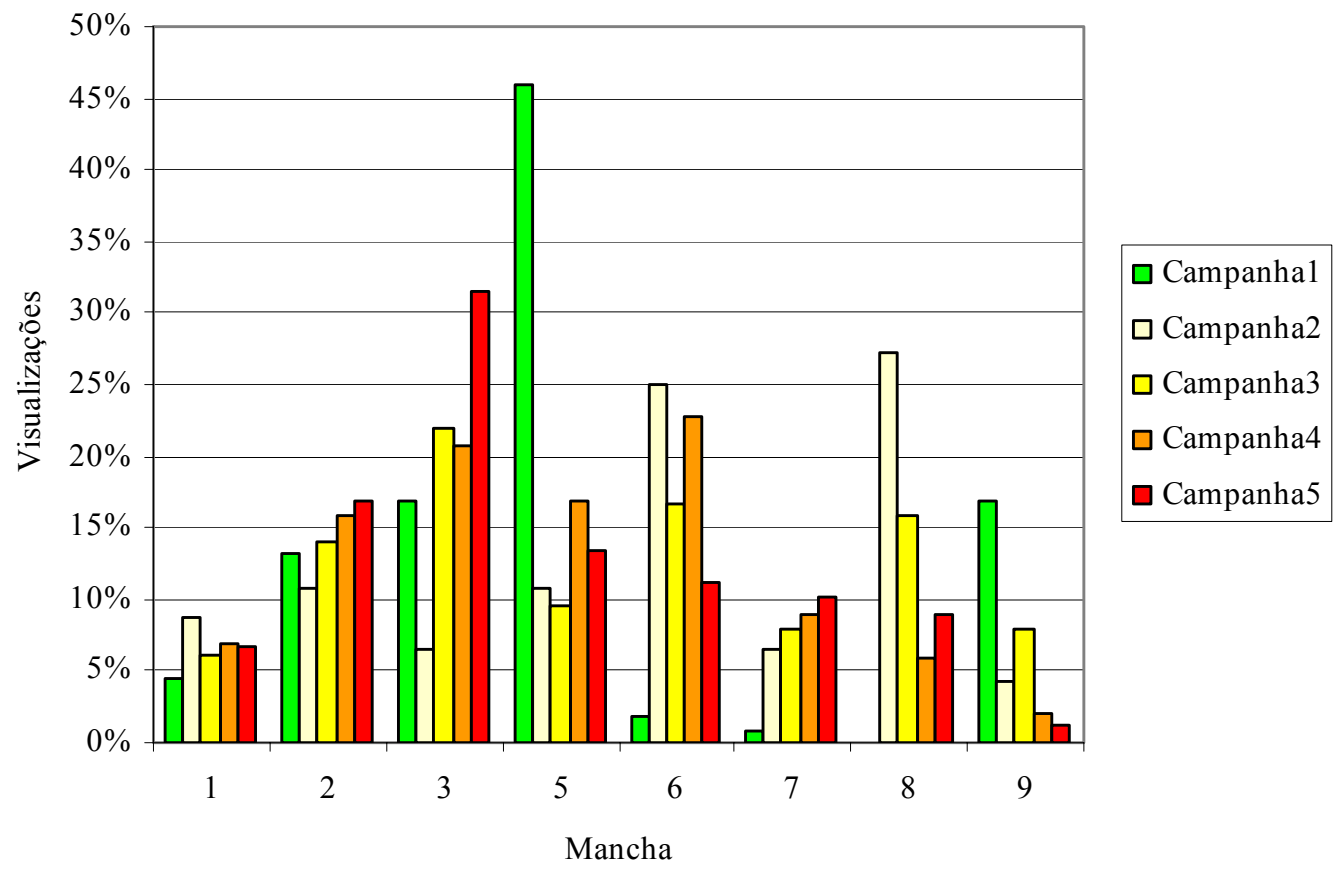

Figura 18 - Freqüência relativa de visualizações de crocodilianos, por campanha, em cada mancha de habitat definida

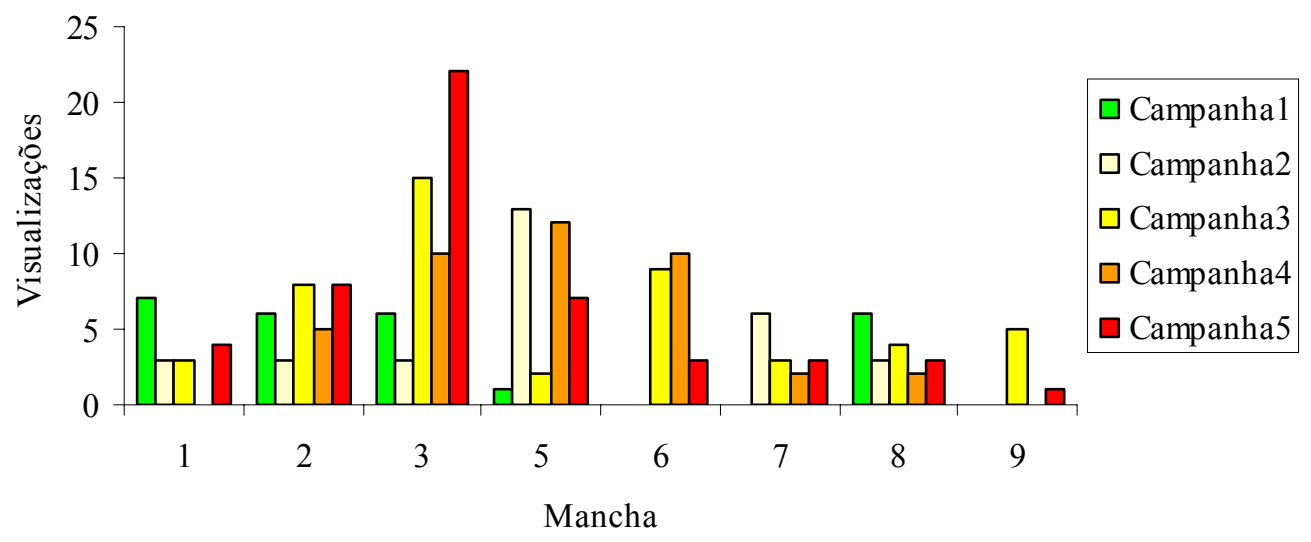

Figura 19 - Número de visualizações de C. crocodilus por campanha e por mancha de habitat 
A Figura 19 apresenta a freqüência absoluta para C. crocodilus nas manchas classificadas ao longo das campanhas. Notam-se oscilações do número de visualizações em todas as campanhas e manchas, com aparente concentração das ocorrências na mancha 3 .

A freqüência absoluta por campanha e mancha para $P$. palpebrosus está representado na Figura 20. Nota-se que apenas a mancha 9 se destaca pelo número reduzido de visualizações. As demais manchas apresentam oscilações não demonstrando claramente tendência à queda ou crescimento do número de ocorrências.

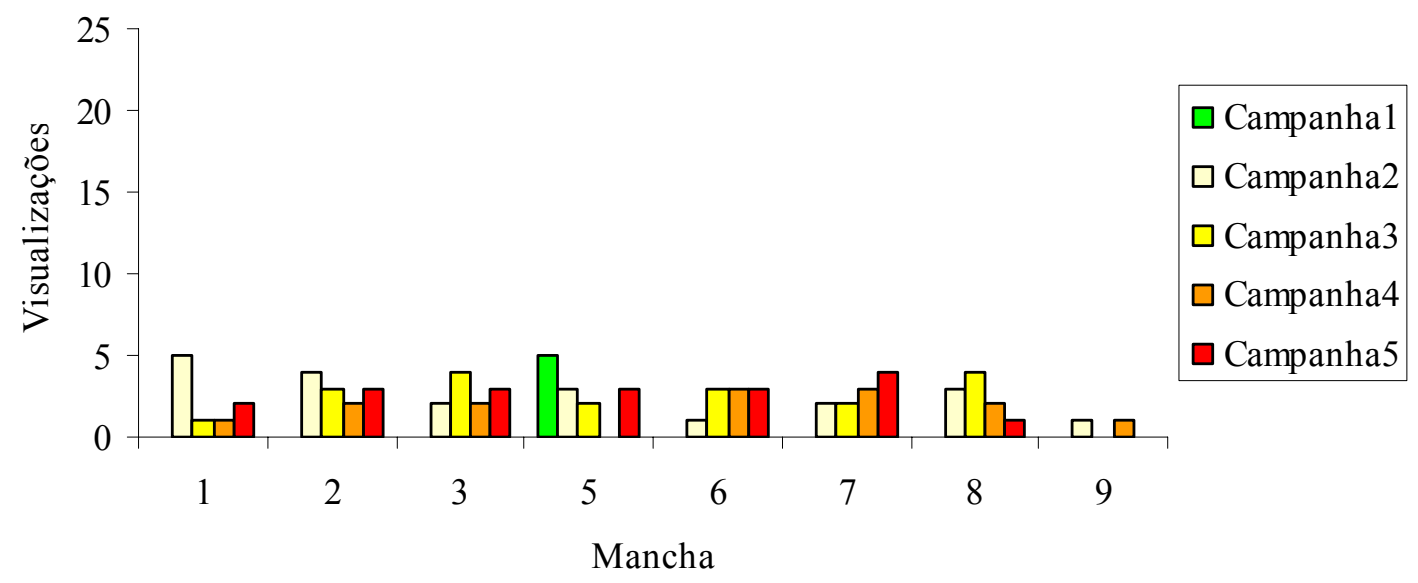

Figura 20 - Número de visualizações de P. palpebrosus por campanha e por mancha de habitat

A Figura 21 traz a freqüência absoluta de visualizações por mancha e campanha para os indeterminados. A mancha 5 na campanha 1 se destaca pelo alto valor apresentado. As demais manchas não apresentam claramente tendências de queda ou aumento quanto à freqüência observada. 


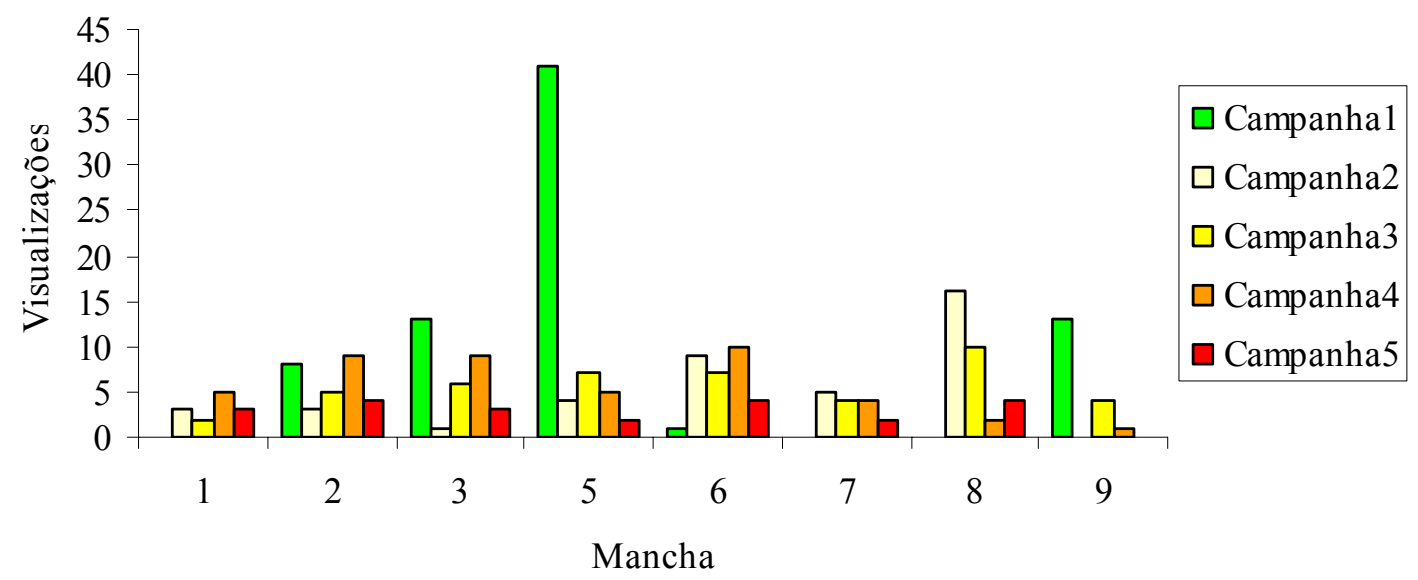

Figura 21 - Número de visualizações de indeterminados por campanha e por mancha de habitat

A Figura 22 traz a freqüência absoluta de visualizações por espécie e mancha somadas todas as campanhas. Nota-se uma distribuição mais homogênea para $P$. palpebrosus, a qual se destaca apenas na mancha 9 pelo baixo número de visualizações. C. crocodilus foi mais freqüente nas manchas 3, 6, 2 e 5 respectivamente, com número de visualizações igual ou superior a $30 \mathrm{em}$ todas estas.

A Figura 23 traz a freqüência relativa por espécie e mancha somadas todas as campanhas. C. crocodilus apresenta freqüência acima de 50\% na mancha 3, e acima de $40 \%$ nas manchas 6,2 e 9. P. palpebrosus apresenta valores superiores a $30 \%$ nas manchas 1 e 7 . 


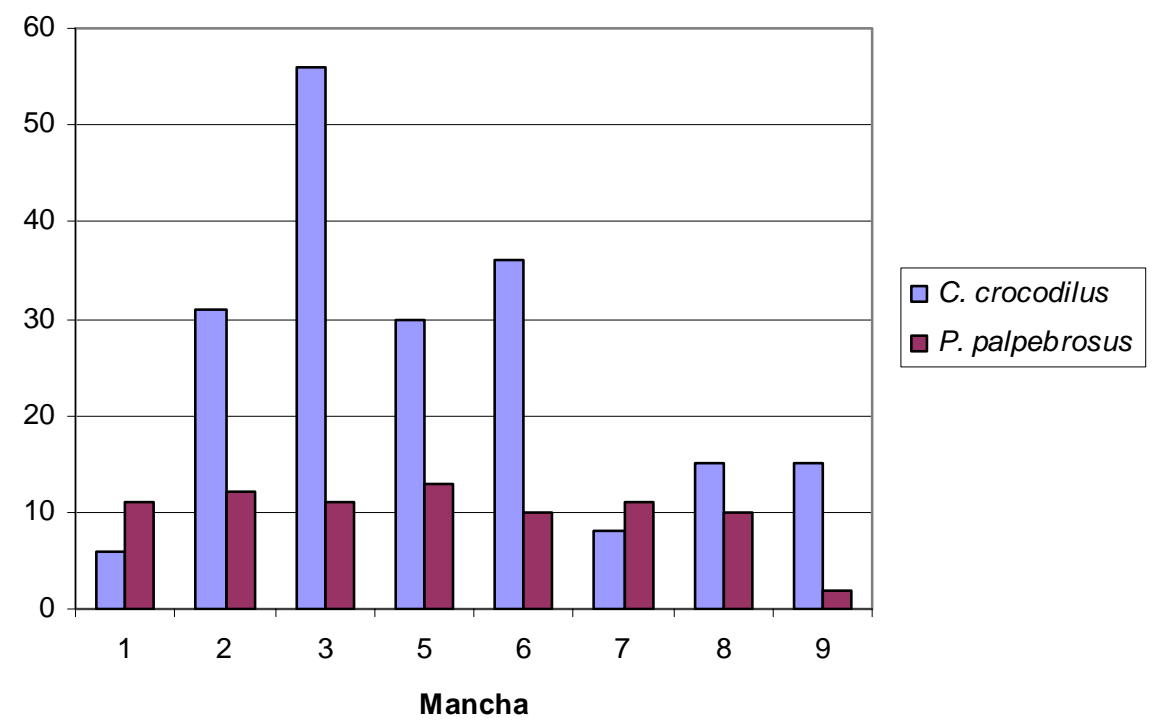

Figura 22 - Freqüência absoluta das espécies, C. crocodilus e P. palpebrosus, nas manchas de habitat determinadas somadas todas as campanhas

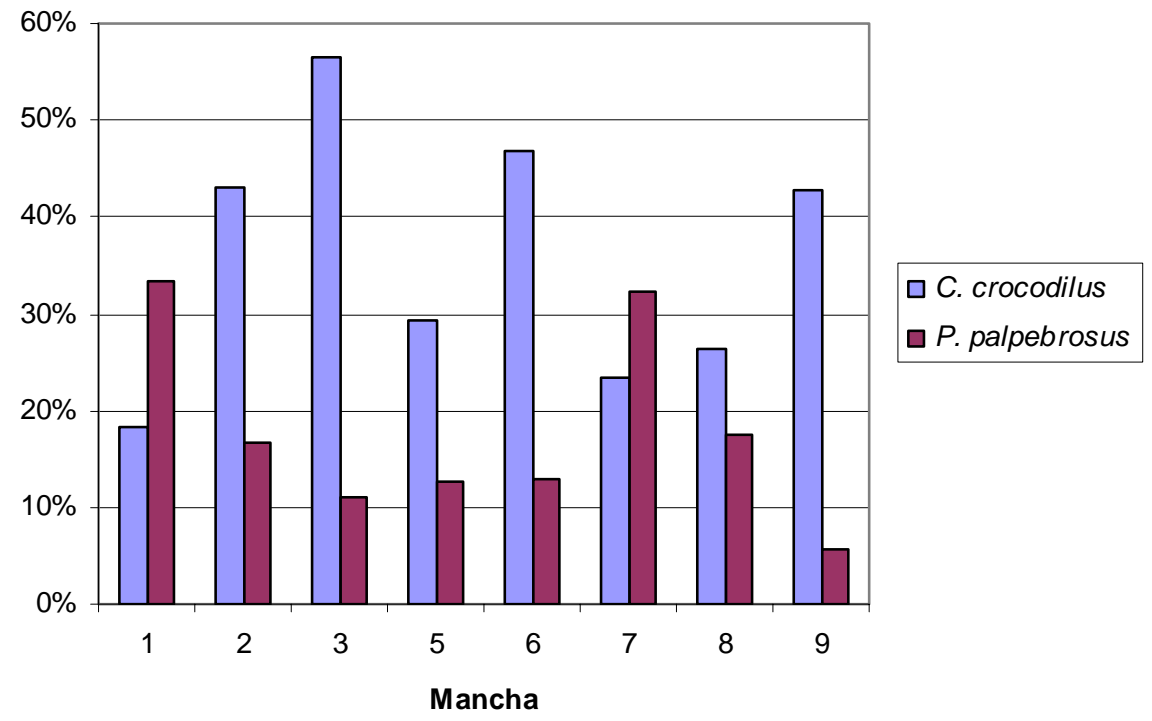

Figura 23 - Freqüência relativa das espécies, C. crocodilus e P. palpebrosus, nas manchas de habitat determinadas somadas todas as campanhas 


\section{DISCUSSÃO}

As duas espécies de crocodilianos encontradas durante a coleta de dados para o estudo foram C. crocodilus e P. palpebrosus. É necessário ressaltar que, apesar de não ter sido encontrado nenhum exemplar de M. niger na área do estudo, sua distribuição geográfica abrange a região em que foi construído o reservatório da UHE de Lajeado (Medem, 1983; Plotkin et al., 1983; Peres \& Carkeek, 1993; Yamashita et al., 1993; Brazaitis et al., 1996). O fato desta espécie não ter sido observada durante a coleta de dados pode estar associada a diversos fatores (e.g. caça predatória, perda de habitat, competição interespecífica) sendo necessários, porém estudos aprofundados para conclusões definitivas. É interessante notar que os moradores e funcionários do empreendimento não souberam informar corretamente quais as espécies de crocodilianos (nomes populares característicos) da região, denominando a todos, simplesmente, de jacaré. Entretanto, alguns moradores relataram ocorrências de jacarés com mais de três metros, observados em anos anteriores a este estudo, denominando-os com o nome popular Jacaré-açu. Como esta espécie apresenta diversas populações fragmentadas (Brazaitis et al., 1996), fato este relacionado provavelmente com os intensos processos de antropização dos ambientes e a forte pressão de caça sobre a espécie (Ross, 1998; Da Silveira, 2002), pode-se supor que a verificação de ocorrência para esta espécie se torna mais difícil por diversos fatores, inclusive por mudanças de comportamento (Verdade, 1996).

A espécie predominante no reservatório, durante o período amostrado, foi $C$. crocodilus, espécie de grande distribuição no Cerrado e Amazônia (Ayarzagüena, 1983; 
Medem, 1983; Webb et al., 1987; Gorzula \& Seijas, 1989; Thorbjarnarson, 1992; Yamashita et al., 1993; Brazaitis et al, 1996; Ross, 1998). A freqüência absoluta de cada espécie durante as campanhas mostra que, independente do número de animais observados, C. crocodilus sempre foi mais freqüente que $P$. palpebrosus e a porcentagem de indivíduos indeterminados, que na primeira campanha estava próxima a $70 \%$, na última reduziu-se para em torno de $24 \%$. A porcentagem total de indivíduos indeterminados (45\%) pode ser explicada: 1) pela dificuldade de aproximação do barco ao animal devido à grande quantidade de matéria vegetal em diversos locais do reservatório; 2) devido a diversos pontos da margem se apresentarem extremamente rasos impedindo a aproximação e 3) pelo fato de muitos animais, ao perceberem o barco, fugirem antes de ser possível sua identificação. A redução na porcentagem de indivíduos indeterminados ocorrida ao longo das campanhas sugere um aumento na adequação dos procedimentos do autor na aproximação e captura.

Ao longo das cinco campanhas realizadas neste estudo o número de animais observados não variou significativamente, com média por campanha de 131,80 animais, tais resultados sugerem a princípio ausência de interferência da condição climática nas visualizações. Apesar do período de estudo não ter completado um ano, as campanhas abrangeram estações secas e chuvosas, ocorrendo visualizações e capturas independente de chuva. É importante salientar que os filhotes foram capturados nas campanhas 3, 4 e 5 (março, maio e julho), correspondendo ao final da estação chuvosa e início da estação seca, tais resultados coincidem com a informações a respeito da época reprodutiva dos crocodilianos (Medem, 1983; Webb et al., 1987; Thorbjarnarson, 1992; 1994).

A captura de exemplares de P. palpebrosus foi mais eficiente se comparada à de C. crocodilus. Tal resultado pode estar relacionado ao fato de C. crocodilus sofrer maior pressão de caça se comparado à P. palpebrosus (Thorbjarnarson, 1992; Ross, 1998). O fato de não ter sido observado nenhum $M$. niger nestas áreas em que existem registros de ocorrência corrobora para tal possibilidade, uma vez que esta espécie é uma das que mais sofre pressão de caça na América do Sul (Da Silveira, 2002).

Estudos de longo prazo, através principalmente de monitoramentos no reservatório além de apreensões de carne e couro podem constatar a ainda ocorrência de 
M. niger na região. Como o presente trabalho se concentrou apenas na área do reservatório, habitats a jusante e montante fora do mesmo, bem como diversos tributários, não foram monitorados, podendo ainda abrigar indivíduos desta espécie. Uma baixa densidade populacional nesta região poderia ser também a explicação para o fato de não ter sido observado $M$. niger no reservatório.

A marcação realizada em 75 animais (43 C. crocodilus e 32 P. palpebrosus) propicia uma oportunidade de continuidade do trabalho para os próximos anos com possibilidade, através de prováveis recapturas, de estimativa dos tamanhos e estruturas populacionais destas duas espécies, informações estas essenciais para a conservação e manejo das populações (Ross, 1998). Tal fato é ainda corroborado pela ocorrência de duas recapturas, não analisadas neste estudo por se mostrarem numericamente insuficientes.

A razão sexual encontrada em $C$. crocodilus foi de 1:1 $(n=43)$, machos e fêmeas respectivamente. Ayarzagüena (1983) sugere que partindo de uma proporção de nascimentos 1:1 na população estudada, as proporções nas classes de tamanho I e II serão também próximas a este valor, provavelmente por ocorrência de predação independente do sexo. Na classe III, segundo o mesmo autor, a tendência é existir mais fêmeas devido a ferimentos causados por comportamentos agonísticos, o que levariam indivíduos à morte. Já na classe IV existiriam apenas machos adultos, porém, os dois únicos C. crocodilus classe IV, encontrados neste presente estudo, foram duas fêmeas que apresentaram 1130 e $1170 \mathrm{~mm}$ de SVL, tais resultados sugerem que a adoção dos mesmos valores referentes às classes de tamanho propostas por Ayarzagüena (1983) pode não representar a população estudada no presente trabalho.

Lance et al. (2000) relata que tanto os estudos antigos (Descourtilz, 1809; Rathke, 1866) como alguns relativamente atuais (Webb \& Smith, 1984; Hutton, 1987) sobre razão sexual nos crocodilianos, tendem a considerar as populações enviesadas em relação ao número de fêmeas. Estes dados não foram confirmados na referida publicação, a qual relata que populações de Crocodilus acutus estudadas em diferentes localidades, apresentam-se enviesadas para o número de machos (Lance et al., 2000). A espécie $P$. palpebrosus aqui estudada apresentou razão sexual 2:1 (machos e fêmeas 
respectivamente) também sugerindo um viés populacional para o número de machos, e corroborando para a não distribuição enviesada de crocodilianos quanto ao número de fêmeas (Thorbjarnarson, 1997). Futuras observações e capturas fornecerão mais informações sobre a razão sexual encontrada para as espécies em questão.

Com o enchimento do reservatório e a formação do lago da UHE, áreas previamente habitadas por crocodilianos, como regiões marginais ao Rio Tocantins e seus tributários foram completamente inundadas. Se verificarmos que o enchimento ocorreu no final do ano de 2001 e início de 2002 (estação chuvosa), época em que os crocodilianos potencialmente estão se reproduzindo (Medem, 1983; Webb et al., 1987; Thorbjarnarson, 1992; 1994), podemos assumir a possibilidade de ninhos terem sido submersos resultando em eventual comprometimento da reprodução das espécies nesta estação.

A observação e captura de 29 filhotes (26 C. crocodilus e 3 P.palpebrosus) no reservatório evidencia ocorrência de reprodução pós-enchimento, indicando nidificação próximo às novas linhas de margens criadas pós-represamento. Tal fato sugere que as fêmeas, mesmo neste ambiente alterado, encontraram novos locais para a desova. Não se deve afirmar, no entanto, que as espécies já se encontram totalmente adaptadas às novas condições ambientais. Um monitoramento ao longo dos anos subseqüentes, com a devida confirmação destes, e provavelmente outros locais como áreas de reprodução, poderá certificar a qualidade destes sítios reprodutivos. Van Horne (1983) salienta que se qualidade de habitat é uma medida de importância do tipo de ambiente para uma determinada espécie, então, ela deveria ser definida não só pela densidade, mas também pela taxa de sobrevivência e reprodução. Desta forma na construção de reservatórios estudos pré-enchimento se mostram de extrema importância para constatação de crescimento ou declínio populacional mediante este impacto ambiental.

A observação de uma ninhada de C. crocodilus em mesmo local (região do Aeroporto) durante três diferentes campanhas pode indicar que a dispersão de filhotes realmente não ocorre nos primeiros meses de vida. O número de filhotes observados nesta ninhada foi diminuindo ao longo das campanhas, podendo indicar dispersão ou 
mesmo predação como já mencionado por Ayarzagüena (1983) e Gorzula \& Seijas (1989).

Nenhum ninho foi localizado apesar dos relatos populares para sua existência. No entanto, no presente estudo poucas saídas diurnas foram realizadas para este fim, caracterizando assim pequeno esforço amostral, necessitando de mais informações de campo para conclusões mais expressivas quanto aos sítios de reprodução das espécies.

A inclusão dos filhotes (classe de tamanho I) nas análises estatísticas referentes ao uso de habitats poderia enviesar os resultados uma vez que tendem em se manterem agrupados por alguns meses após a eclosão. Tal agrupamento provavelmente está relacionado a mecanismos defensivos devido a uma forte pressão de predação sobre esta classe de tamanho. Tal predação sobre os filhotes pode influenciar a distribuição etária da população em um curto espaço de tempo (Ayarzagüena, 1983; Gorzula \& Seijas, 1989; Verdade, 1996).

Não foi encontrada na bibliografia específica divisão em classes de tamanho para $P$. palpebrosus, utilizou-se então as mesmas classes de tamanho empregadas para $C$. crocodilus (estipuladas por Ayarzagüena, 1983). Esta padronização poderia interferir nos resultados devido às diferenças existentes na biologia destas duas espécies. Porém como não foram feitas análises especulativas profundas sobre as classes de tamanho, tal divisão foi realizada com o intuito de estimar, ainda que de modo superficial, a distribuição etária das espécies.

O uso de novos habitats tais como buritizais, matas de galeria, cerrado campo limpo e pastos (todos alagados) foi verificado neste estudo a partir da ocorrência de $P$. palpebrosus e C. crocodilus em locais criados a partir do represamento do Rio Tocantins. Estudos a longo prazo poderão informar quais destes habitats serão utilizados preferencialmente por qual espécie.

Em relação às manchas obtidas pela classificação não supervisionada, embora não tenha havido checagem de campo para averiguação das classes obtidas após a classificação, algumas considerações devem ser feitas. A mancha 4 representa trechos do reservatório com maior profundidade uma vez que está localizada em áreas mais próximas à UHE. 
A mancha 2 pode representar água com presença de sedimentos e/ou com relativa profundidade, uma vez que em alguns trechos evidencia o leito antigo do rio e sua distribuição aparece concentrada nas porções medianas e também à montante do reservatório.Tal mancha é a que apresenta tanto a maior área total como amostrada o que interfere diretamente na densidade.

A mancha 3 aparece em locais próximos às margens do reservatório e dos tributários alagados, bem como, locais próximo à bancos de areia. Possivelmente representa áreas com baixa profundidade sendo então caracterizada como margem rasa. Nota-se uma relativa utilização deste habitat por C. crocodilus, cuja abundância foi a maior para esta espécie. Trata-se da segunda mancha em área amostrada ficando então como a terceira mancha mais densa para C. crocodilus.

A mancha 5 evidencia solo arenoso uma vez que bancos de areia monitorados na margem esquerda da região de Porto Nacional, bem como regiões de antiga extração de areia e praias artificiais recém criadas próximas à cidade de Palmas foram classificados nesta mancha. C. crocodilus e P. palpebrosus apresentaram densidades intermediárias para este habitat, porém quanto à abundância é o principal habitat para $P$. palpebrosus com 13 visualizações.

As manchas 6, 7 e 8 indicam vegetação seca alagada, uma vez que ocorre nas margens alagadas do rio bem como nos tributários, principalmente nas porções mais a montante. A resposta espectral também corrobora para a caracterização destes habitats como locais de vegetação seca. É importante ressaltar que a mancha 7 apresenta maior densidade de $P$. palpebrosus se comparado a C. crocodilus cuja densidade foi a menor entre as demais. A mancha 6, no entanto, apresentou densidades altas para ambas espécies, mostrando que se trata de um habitat cuja ocorrência de crocodilianos desta região é verificada com considerável densidade. Quanto à mancha 8 pode-se inferir que se trata de uma mancha com relativa densidade para C. crocodilus e a segunda maior para $P$. palpebrosus. A área amostrada deste habitat é pequena o que torna a densidade de $P$. palpebrosus alta. Vale salientar que a soma das densidades encontradas neste tipo de habitat, vegetação seca, $\left(27,55 \mathrm{ind} / \mathrm{km}^{2}\right)$ seria a segunda maior observada para $C$. crocodilus, ficando atrás somente da mancha 1 (buritizal). 
A mancha 9 representa provavelmente trechos com presença de gramíneas como, por exemplo, cerrado campo limpo e pastos. Trata-se novamente de um habitat com pequena área amostrada o que eleva a densidade de C. crocodilus que apresentou 15 observações. Vale salientar que na região do Aeroporto, margem esquerda, em todas as campanhas foram observados indivíduos desta espécie próximos a pastos. Quanto a $P$. palpebrosus, devido a somente duas observações neste habitat, caracteriza-se por uma das mais baixas densidades, não demonstrando a princípio uma considerável a utilização deste habitat.

A mancha 1 foi a que apresentou a maior densidade para ambas espécies devido sua pequena área, trata-se de um buritizal alagado acima do aeroporto. Além da presença de crocodilianos nesta mancha foram encontradas diversas redes de pesca, bem como notada a presença de caçadores e/ou pescadores que fugiam ao ouvirem o motor do barco. Tais indícios sugerem ser este um dos principais habitats passíveis a serem ocupados por crocodilianos, com ocorrência maior para $P$. palpebrosus cuja densidade ficou com o valor de $110 \mathrm{ind} . / \mathrm{km}^{2}$. C. crocodilus também apresentou nesta mancha alta densidade 60 ind. $/ \mathrm{km}^{2}$ fato que certamente está relacionada com a reduzida área total bem como amostrada no reservatório.

A distribuição espacial das visualizações em manchas de habitat aquático revela, aparentemente, que C. crocodilus é mais seletivo em termos de uso de habitat do que $P$. palpebrosus. C. crocodilus apresentou maior densidade nas manchas 6, 3 e 9 (descartando a mancha 1 a qual apresenta alta densidade para ambas espécies). Ao que parece, P. palpebrosus, seleciona menos o habitat a ser ocupado e posteriormente colonizado, uma vez que sua distribuição nas manchas classificadas ocorre de maneira menos seletiva que C. crocodilus.

Cabe salientar que tais manchas classificadas pela imagem e caracterizadas posteriormente (método não supervisionado) podem não refletir integralmente as mesmas manchas de habitats aquáticos existentes no período de estudo, uma vez que ao longo da coleta de dados verificou-se a intensa modificação das regiões alagadas monitoradas. Entretanto, acredita-se que esta análise exploratória permite compreender 
em um primeiro momento a relativa distribuição das espécies e conseqüente uso dos novos habitats criados pelo represamento do rio.

Como o presente estudo foi realizado em somente 10 meses pós represamento, tais dados são importantes não para elucidar o processo de colonização, que provavelmente está ocorrendo, mas para uma verificação a curto prazo de como as espécies de crocodilianos simpátricas utilizam novos habitats criados em função de um grande empreendimento hidrelétrico. Somente estudos a longo prazo, através de monitoramentos, estudos de genética populacional, etc, podem realmente inferir sobre o processo de colonização do novo ambiente marginal do reservatório. 


\section{CONCLUSÕES}

Quanto aos objetivos propostos, pode-se concluir que:

1. C. crocodilus e P. palpebrosus são as espécies de crocodilianos encontradas na região do reservatório da UHE de Lajeado no período estudado;

2. Ambas espécies não se mostram relativamente vulneráveis, em um primeiro momento, em função do considerável impacto ambiental ocasionado pelo represamento do rio;

3. A observação de grupos de filhotes recém eclodidos corrobora para o fato das espécies se adequarem ao novo ambiente;

4. C. crocodilus é mais abundante do que P. palpebrosus no reservatório;

5. C. crocodilus é mais seletivo quanto ao uso das manchas de habitats definidos. 


\section{REFERÊNCIAS BIBLIOGRÁFICAS}

AYARZAGÜENA, S.J. Ecología del caiman de anteojos o baba (Caiman crocodilus L.) en los llanos de Apure (Venezuela). Doñana Acta Vertebrata, v.10, n.3, p.1-136, 1983.

BARBRAUD, C.; NICHOLS, J.D.; HINES, J.E.; HAFNER, H. Estimating rates of local extinction and colonization in colonial species and an extension to the metapopulation and community levels. Oikos, v.101, p.113-126, 2003

BRAZAITIS, P. The forensic identification of crocodilian hides and products. In: IUCN. Crocodiles: their ecology, management and conservation. Gland: IUCN/SSC Crocodile Specialist Group. 1989. p.17-43.

BRAZAITIS, P.; REBELO, G.H.; YAMASHITA, C. The status of Caiman crocodilus and Melanosuchus niger populations in the Amazonian regions of Brazil. Amphibia-Reptilia, v.17, p.377-385, 1996.

BRASIL. Instrução normativa $n^{0} 3$ 27/05/2003: Diário Oficial da União, Seção 1, v.101, 28/05/2003, p.88-97. 2003 Lista nacional das espécies da fauna brasileira ameaçada de extinção. 
BRASIL. Ministério do Meio Ambiente. Avaliação e identificação de áreas e ações prioritárias para a conservação, utilização sustentável e repartição dos benefícios da biodiversidade nos biomas brasileiros. Brasília: MMA; SBF, 2002. $404 p$.

BUSACK, S.D.; PANDYA, S. Geographic variation in Caiman crocodiles and Caiman yacare (Crocodylia: Alligotoridae): systematic and legal implications. Herpetologica, v.57, n.3, p.294-312, 2001.

CAMPOS, Z.; COUTINHO, M. MAGNUSSON, W. E. Terrestrial activity of caiman in the Pantanal, Brazil. Copeia, v. 3, p. 628-634, 1993.

CARAMASCHI, U. Nova espécie de Odontophrynus (Reinhardt \& Lÿtken, 1862) do Brasil central (Amphibia, Anura, Leptodactylidae). Boletim do Museu Nacional, Nova Série Zoologia, v.367, p.1-8, 1996.

COLLI, G.R.; PÍRES JUNIOR., A.K.; CUNHA, H.J. A new species of Tupinambis (Sauria: Teiidae) from central Brazil, with an analysis of morphological and genetic variation in the genus. Herpetologica, v.54, p.477-492, 1998.

COUTINHO, L.M.; MIRANDA, H.S.; MORAIS, H.C. O bioma do Cerrado e o fogo: I - Caracterização. São Paulo: Instituto de Estudos Avançados, 2002. 46p. (Série Ciências Ambientais, 20).

DA SILVEIRA, R. Conservação e manejo do Jacaré-açu (Melanosuchus niger) na Amazônia Brasileira. In: VERDADE, L.M.; LARRIERA, A. (Ed.). La conservacion y el manejo de caimanes y cocodrilos de America Latina. Piracicaba: CN Editoria, 2002. v.2, p. 61-78. 
DA SILVEIRA, R.; MAGNUSSON, W.E.; CAMPOS, Z. Monitoring the distribution, abundance and breeding areas of Caiman crocodilus crocodilus and Melanosuchus niger in the Anavilhanas Archipelago, Central Amazonia, Brazil. Journal of Herpetology, v.31, p.514-520, 1997.

DARRYL, I.; MACKENZIE, D.I.; NICHOLS,J.D.; HINES, J.E.; KNUTSON, M.G.; FRANKLIN, A.B. Estimating site occupancy, colonization, and local extinction when a species is detected imperfectly. Ecology, v.84, n.8, p.2200-2207, 2003.

DESCOURTILZ, M.E. Histoire naturelle du Crocodile de Saint-Domingue. Voyage d'un naturaliste. Paris: Dufart, 1809.

EASTMAN, J.R. Idrisi 32. Worcester: Clark Labs University, 1999.

ENVIRONMENTAL SYSTEMS RESEARCH INSTITUTE. Using ArcView GIS. New York: ESRI Press, 1996. 340p.

FREEMARK, K.; BERT, D.; VILLARD M. Patch-, landscape-, and regional-scale effects on biota. In: GUTZWILLER, K.J. (Ed.). Applying landscape ecology in biological Conservation. New York: Springer, 2002. p.58-83.

GORZULA, S.; SEIJAS, A.E. The common caiman. In: IUCN. Crocodiles: their ecology, management and conservation. Gland: IUCN/SSC Crocodile Specialist Group, 1989. p.44-61.

HALL, P.M. Dangerous to man? A record of an attack by a black caiman (Melanosuchus niger) in Guyana. Herpetological Review, v.22, n.1, p.9-11, 1991. 
HERRON, J.C. Body size, spatial distribution, and microhabitat use in the Caimans, Melanosuchus niger and Caiman crocodilus, in a Peruvian lake. Journal of Herpetology, v.28, p.508-513, 1994.

HEYER, R.H. On frog distribution patterns east of the Andes. In: VANZOLINI, P.E.; HEYER, H. (Ed.). Proceedings of a Workshop on Neotropical Distribution Patterns. Rio de Janeiro: Academia Brasileira de Ciências, 1988. p.245-273.

HÖFLING, E.; OLIVEIRA, A.M. DE S.; TREFAUT, M.; TRAJANO, E.; ROCHA, P.L.B. Chordata: manual para um curso prático. São Paulo: EDUSP, 1995. 243p.

HOUAISS, A. Dicionário Houaiss da Língua Portuguesa. Rio de Janeiro: Editora Objetiva, 2001. 3008p.

HUTTON, J.M. Incubation temperatures, sex ratios and sex determination in a population of Nile crocodiles (Crocodylus niloticus). Journal of Zoology, v. 211, p.143-155, 1987.

IMS, R.A.; YOCCOZ, N.G. Studying transfer processes in metapopulaitons. Emigration, migration and colonization. In: HANSKI, I.A.; GILPIN, M.E. Metapopulation biology: ecology, genetics, and evolution. San Diego: Academic Press, 1997. p.247265 .

INTERNATIONAL UNION FOR CONSERVATION OF NATURE AND NATURAL RESOURCES. The IUCN Amphibia-Reptilia red data book Part 1. Testudines, crocodylia, rhynchocephalia. Gland, 1982.

KING, F.W.; BURKE, R L. Crocodilian, tuatara and turtle species of the world: a taxonomic and geographic reference. Washington: Assoc. Systematics Collections, 1989. 216p. 
LACHER JUNIOR., T. E.; ALHO, C.J.R. Terrestrial small mammal richness and habitat associations in an Amazon Forest - Cerrado contact zone. Biotropica, v. 33, n.1, p. 171-181, 2001.

LANCE, V.A.; ELSEY, R.M.; LANG, J.W. Sex ratios of American alligators (Crocodylidae): male or female biased? Journal of Zoology, v. 252, p. 71-78, 2000.

LANG, J. W. Crocodilian behaviour: implications for management. In: WEBB, G.J.W.; MANOLIS, S.C.; WHITEHEAD, P.J. (Ed.). Wildlife management: crocodiles an alligators. Chipping Norton: Surrey Beatty, 1987. p. 273 - 294.

LIKENS, G.E. Long-term studies in ecology: approaches and alternatives. New York: Springer - Verlag, 1989. 214 p.

McCUllough, D.R. (Ed.). Metapopulations and wildlife conservation. Covelo: Island Press, 1996. 432 p.

MAGNUSSON, W.E. Size estimates of crocodilians. Journal of Herpetology, v.16, p.121-130, 1983.

MAGNUSSON, W.E. The peculiarities of crocodilian population dynamics and their possible importance for management strategies. In: 1986/Crocodiles: Proceedings $7^{\text {th }}$ Working Meeting Crocodile Specialist Group. Venezuela: FUDENA/IUCN, 1986. p.434-442.

MAGNUSSON, W.E. A conservação de crocodilianos na América Latina. In: LARRIERA, A.; VERDADE, L.M. (Ed.). La conservacion y el manejo de caimanes y cocodrilos de America Latina. Piracicaba: CN Editoria, 2002. v.1, p. $5-17$. 
MANGINI, P.R.; NICOLA, P.A. Captura e marcação de animais silvestres. In: CULlEN JUNIOR, L.; RUDRAN, R.; VAlLADARES-PADUA, C. (Org.). Métodos de estudos em biologia da conservação e manejo da vida silvestre. Curitiba: Editora UFPR, 2003 p.91-124.

MEDEM, F. Los Crocodylia de Sur América. Bogotá: Ed. Carrera, 1983. v.2, 270p.

MORRISON, M.L.; MARCOT, B.G.; MANNAN, R.W. Wildlife habitat relationships: concepts and applications. 2.ed. Madison: The University of Wisconsin Press, 1998. 435p.

MOURÃO, G.M.; MAGNUSSON, W.E. Uso de levantamentos aéreos para o manejo de populações silvestres. In: VALLADARES-PADUA, C.; BODMER, R.E. (Ed.). Manejo e conservação da vida silvestre no Brasil. Belém: Sociedade Civil Mamirauá, 1997. p.23-33.

MÜLLER, A.C. Hidrelétricas, meio ambiente e desenvolvimento. São Paulo: Ed. Makron Books, 1995. 412p.

PARSONS, P.A. Features of colonizing animals: phenotypes and genotypes. In: GRAY, A.J.; CRAWLEY, M.J.; EDWARDS, P.J. (Ed.). Colonization, succession and stability. Oxford : Blackwell Scientific Publications, 1987. p.133-154.

PERES, C.A.; CARKEEK, A.M. How caimans protect fish stocks in western Brazilian Amazônia - A case for maintaining the ban on caiman hunting. Oryx, v.27, n.4, p.225-230. 1993.

PIFFER, T.R.O; VERDADE, L.M. Caiman latirostris (broad - snouted caiman) courtship behavior. Herpetological Review, v. 33, n.2, p 132-133, 2002. 
PIÑA, C.I.; LARRIERA A.; SIROSKI, P. Cocodrilos de la región litoral: especies, distribución geográfica, modo de vida. Insugeo, v.17, p.317-322, 2004.

PLOTKIN, M.J.; MEDEM F.; MITTERMEIER, R.A.; CONSTABLE, I.A. Distribution and conservation of the black caiman (Melanosuchus niger). In: RHODIN, A.; MITAYA, K. (Ed.). Advances in herpetology and evolutionary biology. Cambridge: Museum of Comparative Zoology, 1983. p.695 - 705.

POMBAL JUNIOR, J.P.; BASTOS, R.P. Nova espécie de Scinax (Wagler, 1830) do Brasil central (Amphibia, Anura, Hylidae). Boletim do Museu Nacional, Nova Série Zoologia, v.371, p.1-11. 1996.

POUGH, F.H.; HEISER, J.B.; MCFARLAND, W.N. A vida dos vertebrados. São Paulo: Atheneu, 1993. 839p.

POUGH, F.H.; ANDREWS, R.M.; CADLE, J.E.; CRUMP, M.L.; SAVITSKY, A.H.; WELLS, K.D. Herpetology. New Jersey : Prentice-Hall, 1998. p.577.

RATHKE, C. Untersuchungen uber die entwickelung und den korperbau der krocodile. Braunschweig: F. Vieweg, 1866.

REDFORD, K.H.; FONSECA, G.A.B. da. The role of gallery forests in the zoogeography of the cerrado's non-volant mammalian fauna. Biotropica, v.18, n.2, p. 126-135, 1986.

RICKLEFS, R.E. A economia da natureza. 5. ed. Rio de Janeiro: Guanabara Koogan, 2003. 470p.

RODRIGUES, M.T. A new species of Micrablepharus (Squamata: Gymnophtalmidae), from Brazil. Herpetologica, v.52, p.535-541, 1996. 
ROSS, J.P. Crocodiles: status survey and conservation action plan. $2^{\mathrm{a}}$ ed. Gland: The World Conservation Union, 1998. 96p.

SAVARD, J.L.; CLERGEAU, P.; MENNECHEZ, G. Biodiversity concepts and urban ecosystems. Landscape and Urban Planning, v.48, p.131-142, 2000.

SCOTT JUNIOR, N.J.; AQUINO, A.; FITZGERALD, L.A. Distribution, habits and conservation of the caiman (Alligatoridae) of Paraguay. Vida Silvestre Neotropical, v.2, p.43-51, 1990.

STRUSSMAN, C.; CARVALHO, M.A. Two new species of Cercolophia (Vanzolini, 1992) from the state of Mato Grosso, western Brazil (Reptilia, Amphisbaenia, Amphisbaenidae). Museo Regional de Scienze Naturali, Bolletino Turin, v.2, n.18, p. 487-505, 2000.

THORBJARNARSON, J.B. Crocodiles: an action plan for their conservation. Gland: The World Conservation Union, 1992. 96p.

THORBJARNARSON, J.B. Reproductive ecology of the Spectacled (Caiman crocodilus) in the Venezuelan Llanos. Copeia, n.4, p.907-919, 1994.

THORBJARNARSON, J.B. Are crocodilian sex ratios female biased? The data are equivocal. Copeia, p.451-455, 1997.

TOCANTINS. Secretaria do Planejamento e Meio Ambiente, Diretoria de Zoneamento Ecológico-Econômico - DEZ. Atlas do Tocantis: subsídios ao planejamento da gestão territorial. Palmas: Seplan, 1999. 49p. 
VAN HORNE, B. Approaches to habitat modelling: the tensions between pattern and process and between specificity and generality. In: SCOTT, J.M.; HEGLUND, P.J.; MORRISON, M.L.; HAUFLER, J.B.; RAPHAEL, M.G.; WALL, W.A.; SAMSON, F.B. (Ed.). Predicting species occurrence: issues of accuracy and scale. Washington: Island Press, 2002. p.63-72.

VANZOLINI, P.E. A new species of Amphisbaena from the state of São Paulo, Brasil (Reptilia, Amphisbaenia, Amphisbaenidae). Papéis Avulsos de Zoologia, v.39, p.29-32, 1994.

VANZOLINI, P.E. A new species of Amphisbaena from the state from Mato Grosso, Brasil (Reptilia, Amphisbaenia, Amphisbaenidae). Papéis Avulsos de Zoologia, v.39, p.217-221, 1995.

VANZOLINI, P.E. The silvestri species group of Amphisbaenia, with the description of two new Brazilian species (Reptilia, Amphisbaenia). Papéis Avulsos de Zoologia, v.40, p.65-85. 1997.

VANZOLINI P.E.; HEYER, R.H. In: Proceedings of a workshop on Neotropical distribution patterns. Rio de Janeiro: Academia Brasileira de Ciências. 1988, p. 1936.

VERDADE, L.M. The influence of hunting pressure on the social behavior of vertebrates. Revista Brasileira de Biologia, v.56, n. 1, p.1-13, 1996.

VERDADE, L.M. Manejo e Conservação do Jacaré-de-Papo-Amarelo (Caiman latirostris) no Estado de São Paulo. In: VALLADARES-PADUA, C.; BODMER, R.E. (Ed.). Manejo e conservação da vida silvestre no Brasil. Belém: Sociedade Civil Mamirauá. 1997. p. 222-232. 
WEBB, G.J.W.; MANOLIS, S.C.; WHITEHEAD, P.J. Wildlife management: crocodiles and alligators. Chipping Norton: Surrey Beaty, 1987. 552p.

WEBB, G.J.W.; SMITH, A.M.A. Sex ratio and survivor-ship in the Australian freshwater crocodile, Crocodylus johnstoni. Symposium of Zoological Society of London, n.52, p.319-355, 1984.

WIENS, J.A. Metapopulation dynamics and landscape ecology. In: HANSKI, I.A.; GILPIN, M.E. (Ed.). Metapopulation biology: ecology, genetics and evolution. São Diego: Academic Press, 1996. p.43-62.

YAMASHITA, C. Temperatura corpórea de atividade noturna em Caiman crocodilus yacare e C. C. crocodilus (Crocodilia, Alligatoridade). Rio Claro, 1993. 56p. Dissertação (Mestrado) - Instituto de Biociências, Universidade Estadual Paulista "Júlio de Mesquita Filho".

YAMASHITA, C.; BRAZAITIS, P.; REBELO, G.H. The crocodilians of Brazil and the identification of the species. In: VERDADE, L.M.; PACKER, I.U.; ROCHA, M.B.; MOLINA, F. B.; DUARTE, P.G.; LULA, L.A.B.M. (Ed.). Anais do $3^{\circ}$ Workshop sobre Conservação e Manejo do Jacaré-de-papo-amarelo. Piracicaba, São Paulo. 1993. p 207-220.

ZAR, J. H. Bioestatistical analysis. 4. ed. New Jersey: Prentice-Hall, 1999. 718p.

ZUG, G.R.; VITT, L.J.; CALDWELL J.P. Herpetology: an introductory biology of amphibians and reptiles. 2 ed. San Diego: Academic Press, 2001. 630 p. 